Vol.15, No. 54, January, 2020, 394-415

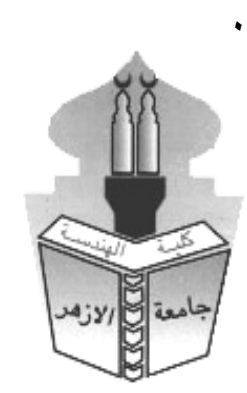

\title{
KEEPING THE EGYPTIAN ARCHITECTURAL HERITAGE FROM THE VIEW OF (LAW 144 - 2006)
}

\author{
Yasser Mohamed Salah EIMograby* and Rofaida Mohy Eldeen El Attar \\ Architecture Department, Faculty of fine arts- Minia university, Minia, Egypt \\ *Corresponding author E-mail: dr.yasserelmagraby@yahoo.com
}

\begin{abstract}
Buildings with Architectural Heritage are considered as an important part of the Egyptian cultural inherited that the government seeking for keeping them through (Law 144 - 2006) Specially buildings that were constructed in old eras such as ( Mohamed Ali Basha era )till the beginning of the $20^{\text {th }}$ Century as this interval is known as prosperity eras and the change of the Architectural thoughts in Egypt .

These buildings contain Aesthetic and Architectural Values which are found in their Architectural elements and represent a unique style that make these buildings as an artistic Antiques, So a National direction appears for keeping this unique Architectural wealth which make the two researchers reach to some recommendations, some important suggestions and some additions on (Law 144 - 2006) which warning from adding or destroying these buildings.

As the two researchers thought that adding can be formed in some cases but under special conditions with the attention of Specialists. Oslo the two researchers suggest forming sanctions on each archeological building exposed to carelessness or destroying to keep The Egyptian Architectural Heritage from lost.
\end{abstract}

\section{KEYWORDS : Architectural Heritage, Law 144 by 2006 AD, Building Re qualification, Architectural keeping, Old Buildings, Originality and Contemporary Palaces.}

$$
\begin{aligned}
& \text { الحفاظ علي التراث المعماري المصري من منظور قانون رقم ع ؛ السنةج . . بم } \\
& \text { ياسر محمد صلاح الدين محمود المغربي* و رفيدة محي الدين تحمد أحمد العطار }
\end{aligned}
$$

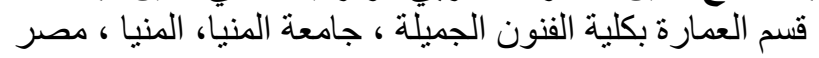

$$
\begin{aligned}
& \text { E-mail: dr.yasserelmagraby@yahoo.com : البريد الاليكتروني للباحث الرئيسئ ، }
\end{aligned}
$$

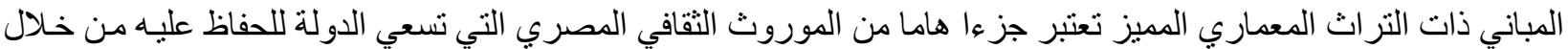

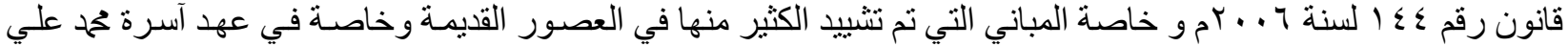

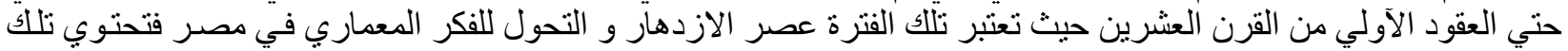

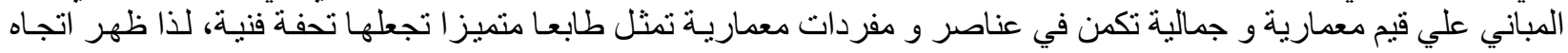

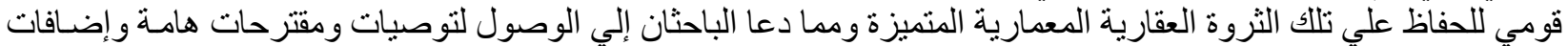

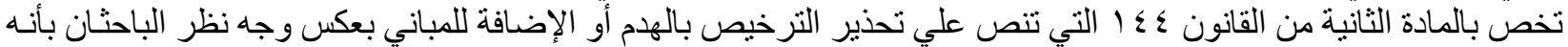


يسمح ولكن في حالات مقننة وتكون تحت إثر اف الجهات المعنية وكذلك توصيات بالعقوبات علي كل مبني أثري يهذدم ويههل

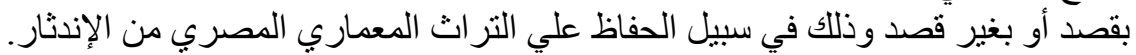

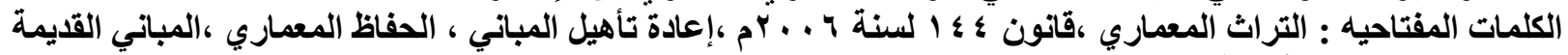

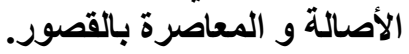

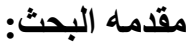

المجتمعات الانسانية تمر بالعديد من الحضار ات و الثقافات خلال العصور المختلفة و ينتج عنها مباني تلبي الاحتياجات الوظيفية

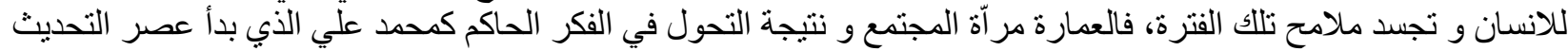

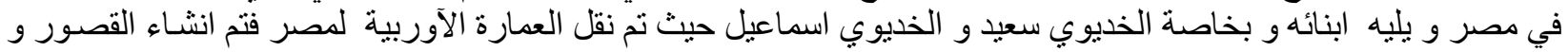

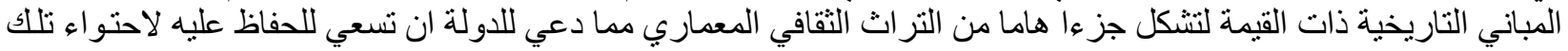

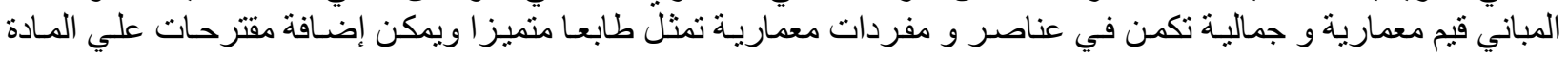

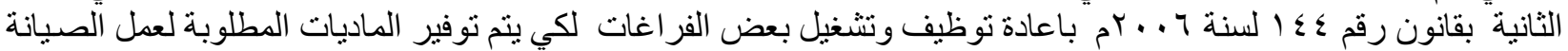

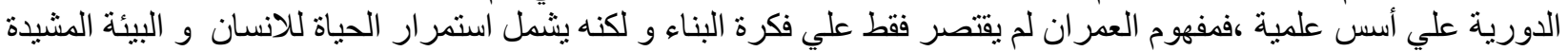

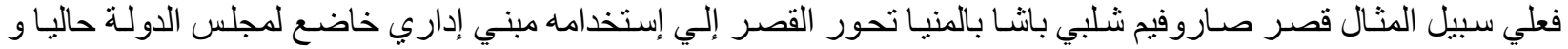

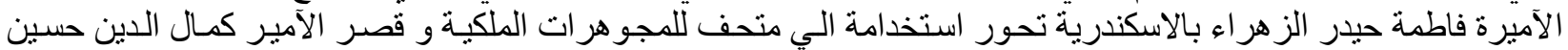
أصبح وزارة للخارجية ( المبني القديم الأبندة ).

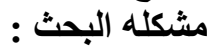

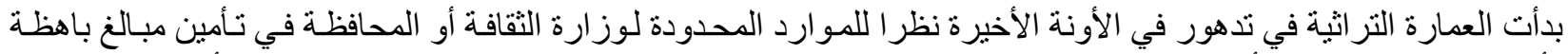

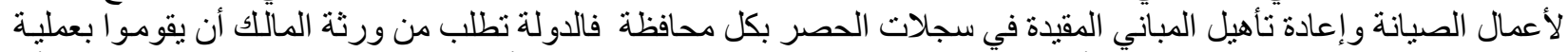

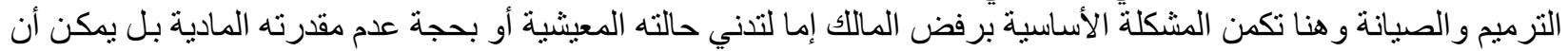

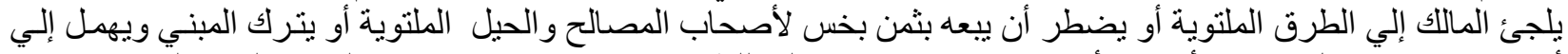

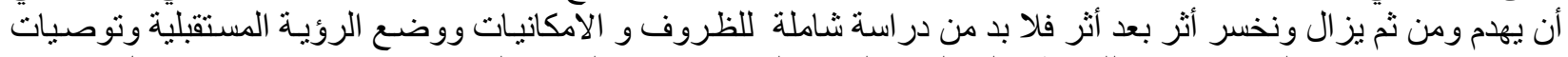

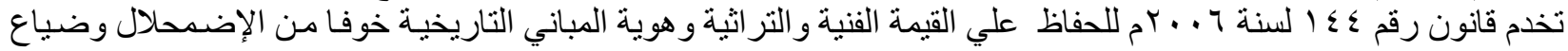

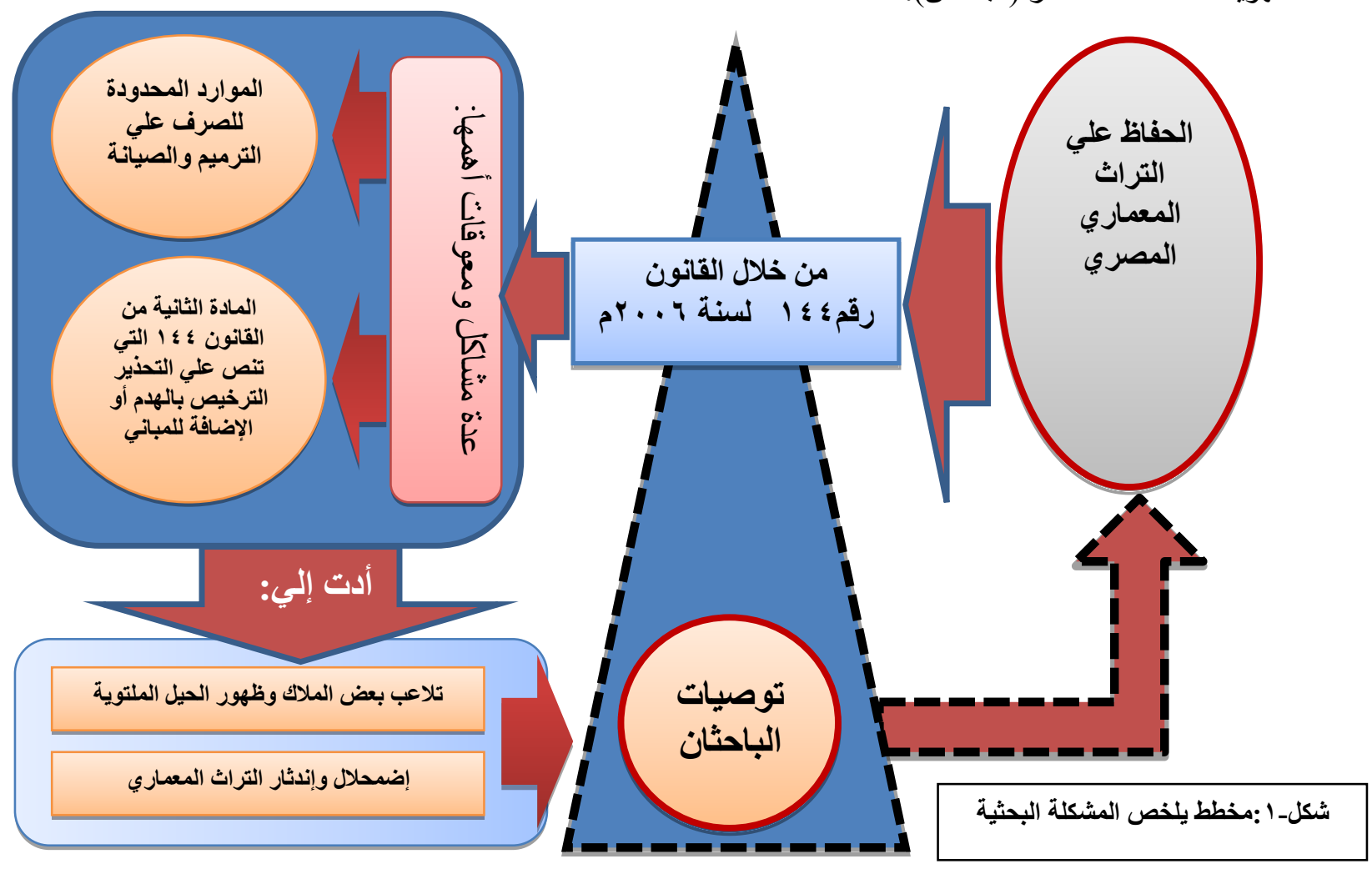




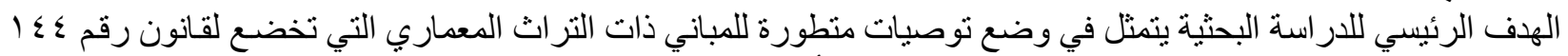

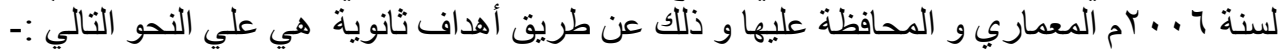

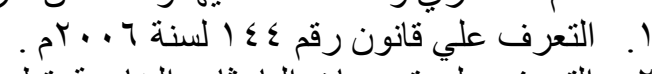

r. التعرف علي توصيات الباحثنان الخاصة بتطوير تطبيق المادة الثانية و التي تنص علي التحذير الترخيص بالهدم أو

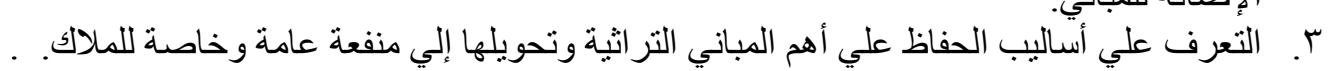

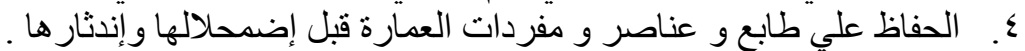

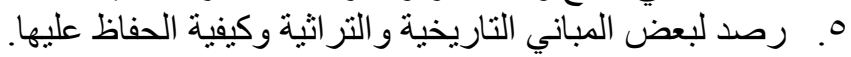

منهج البحث:

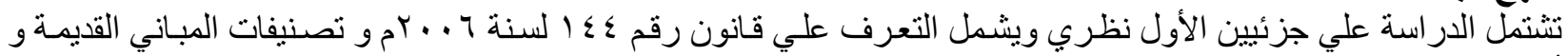

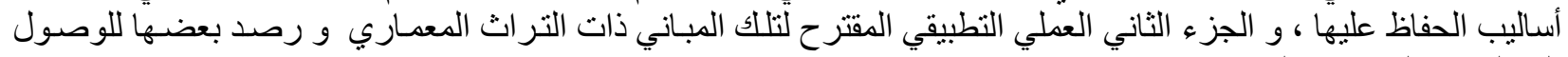
الي النتيجة البحثية ثم التوصيات.

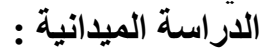

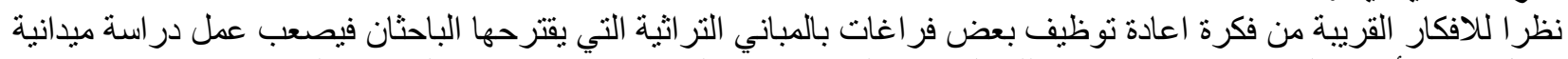

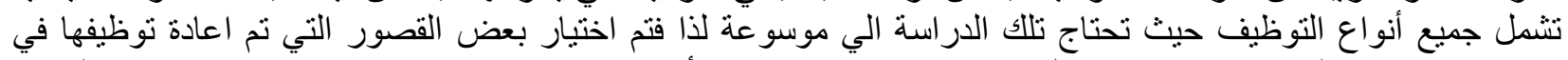

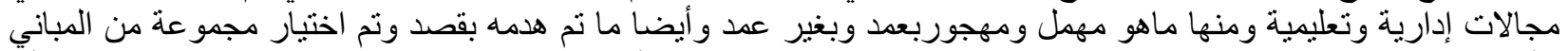

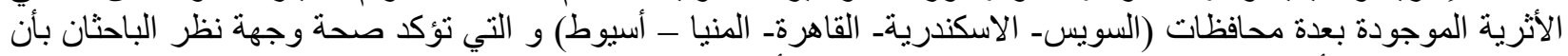

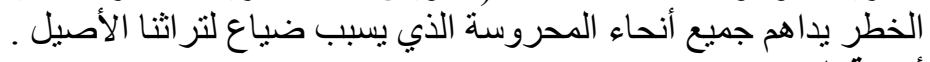

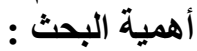

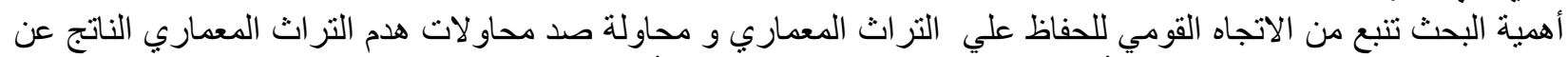

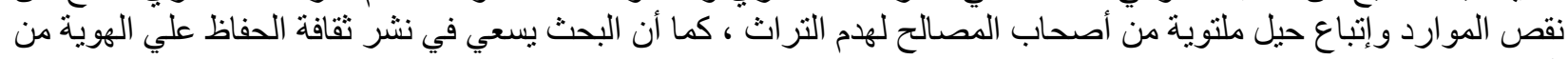

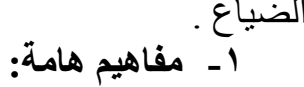 -}

التراث المعماري هو كل ما شيده الآجداد و تختلف المباد المباني تبعا لقدمهاو الأزمنة التاريخية التي تنتمي اليها تللك المباني و الفنون

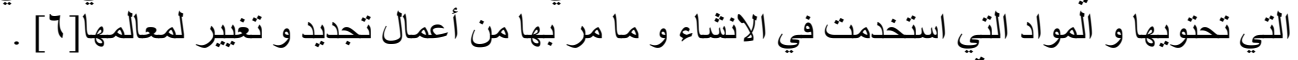

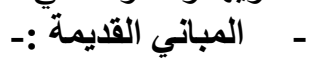

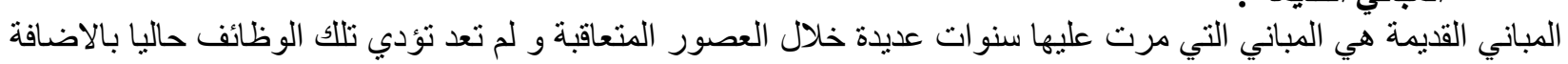

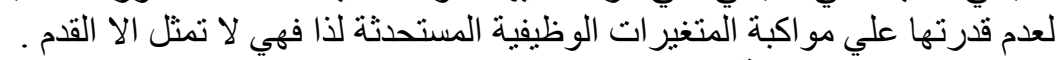

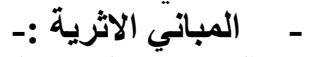

المبني الآثري هو المبني الاثرية القديم و لكنه ذو قيمة بالاضافة الي أنه مر عليه مائة عام أو أكثر و له دور في رصد و توثيق تونيق تاريخ

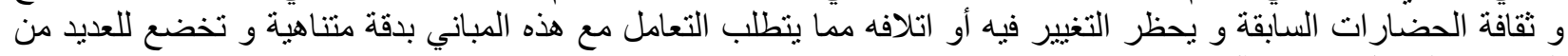

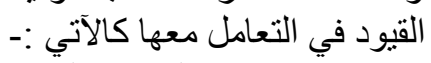

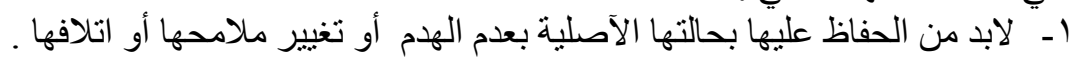

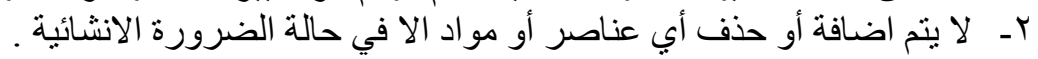

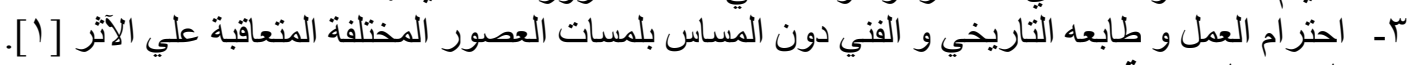

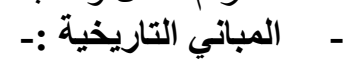

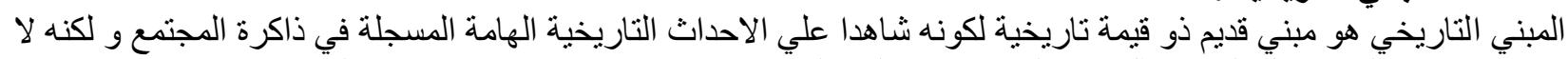

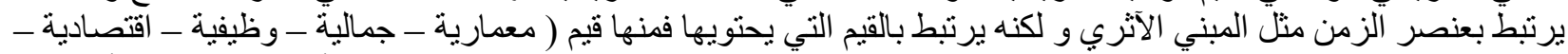

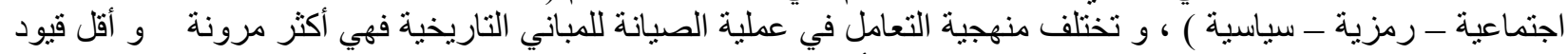

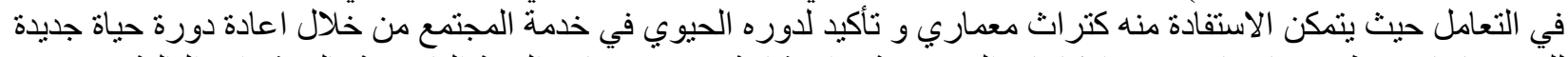

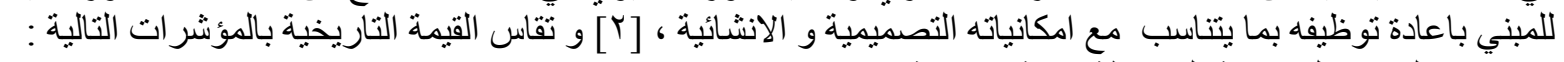

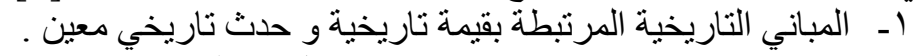

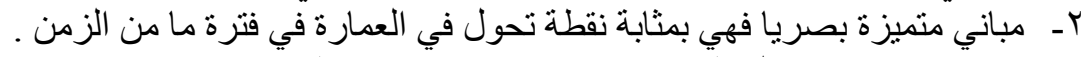

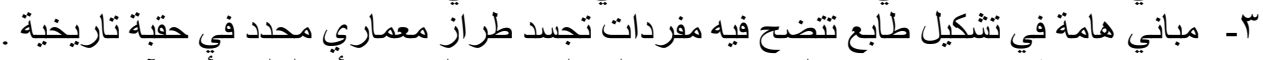

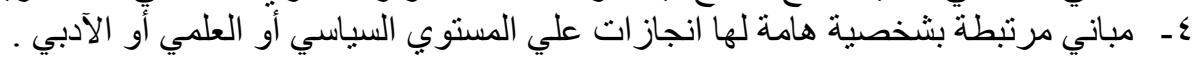


هو العمل علي تقليل استنزاف ثروات و موارد الطبيعة عن طريق الاعتماد علي الموادو الموارد المتجددة و الحفاظ علي

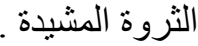
-

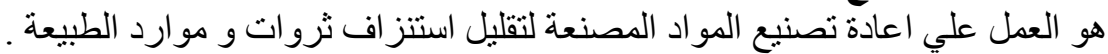

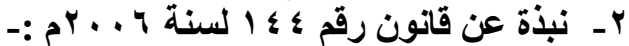

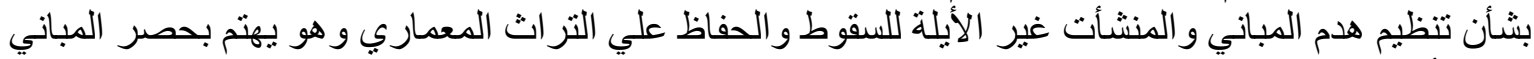

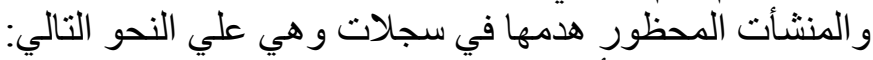

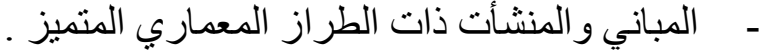

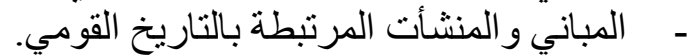

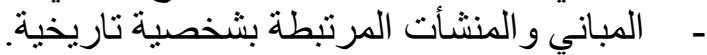

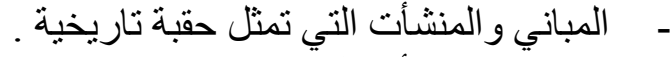

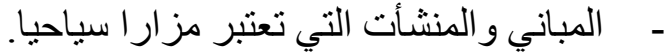

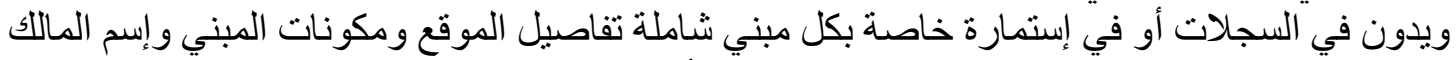

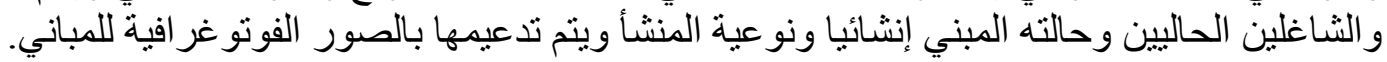

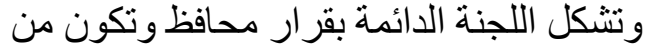

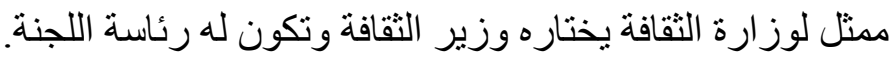
ممثل لوز ارة الإسكان و المر افق يختاره الوزير الوزير المختص بشُونئون الإسكان. إثنين يمثلان المحافظة. خمسة من أعضاء هيئات التدريس بالجامعات المتخصصين في مجالات الهندسة والفنون يختار هم رؤساء

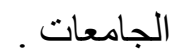

وتختص اللجنة بعمل الحصر ومر اجعته ويرفع للمحافظ ومن ثم إلي رئيس مجلس الوزر اءهالمصدر :( الجريدة

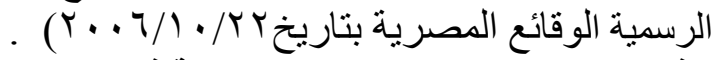

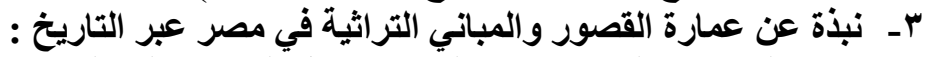

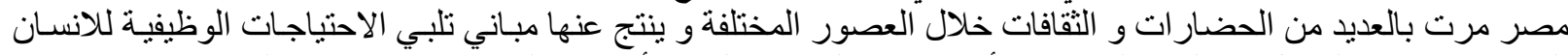

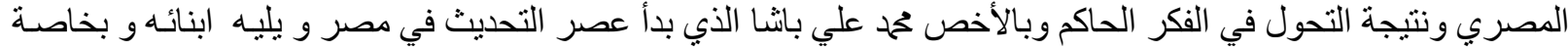

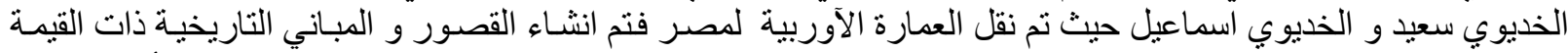

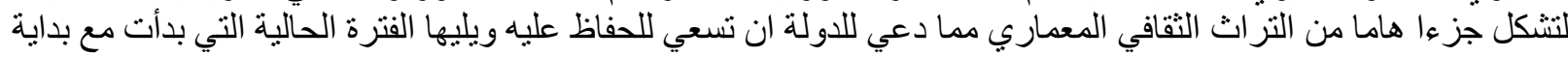
الجدول- ا :نبذة عن عمارة القصور والمباني التراثية في مصر عبر التاريخ ·

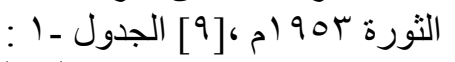

\begin{tabular}{|c|c|c|c|}
\hline فترة القصور التاريخية الثالثة & فترة القصور التاريخية الثانية أثناء & 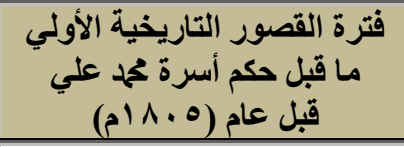 & \\
\hline 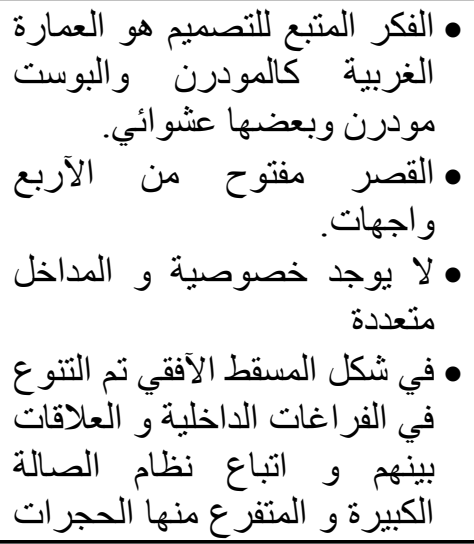 & 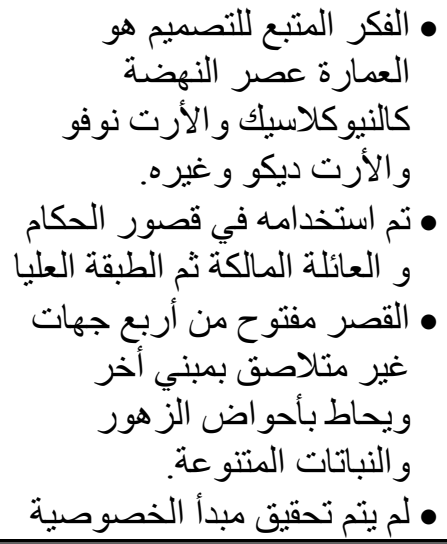 & 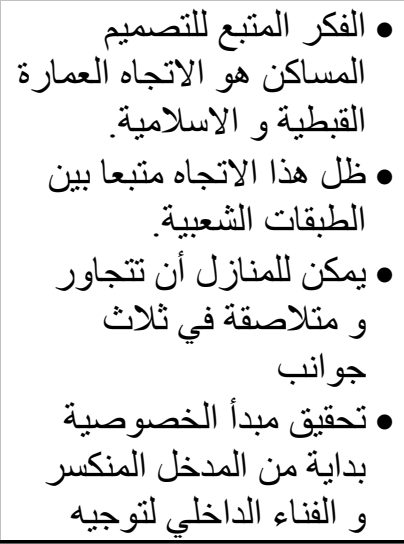 & الفكر التصميمي \\
\hline
\end{tabular}




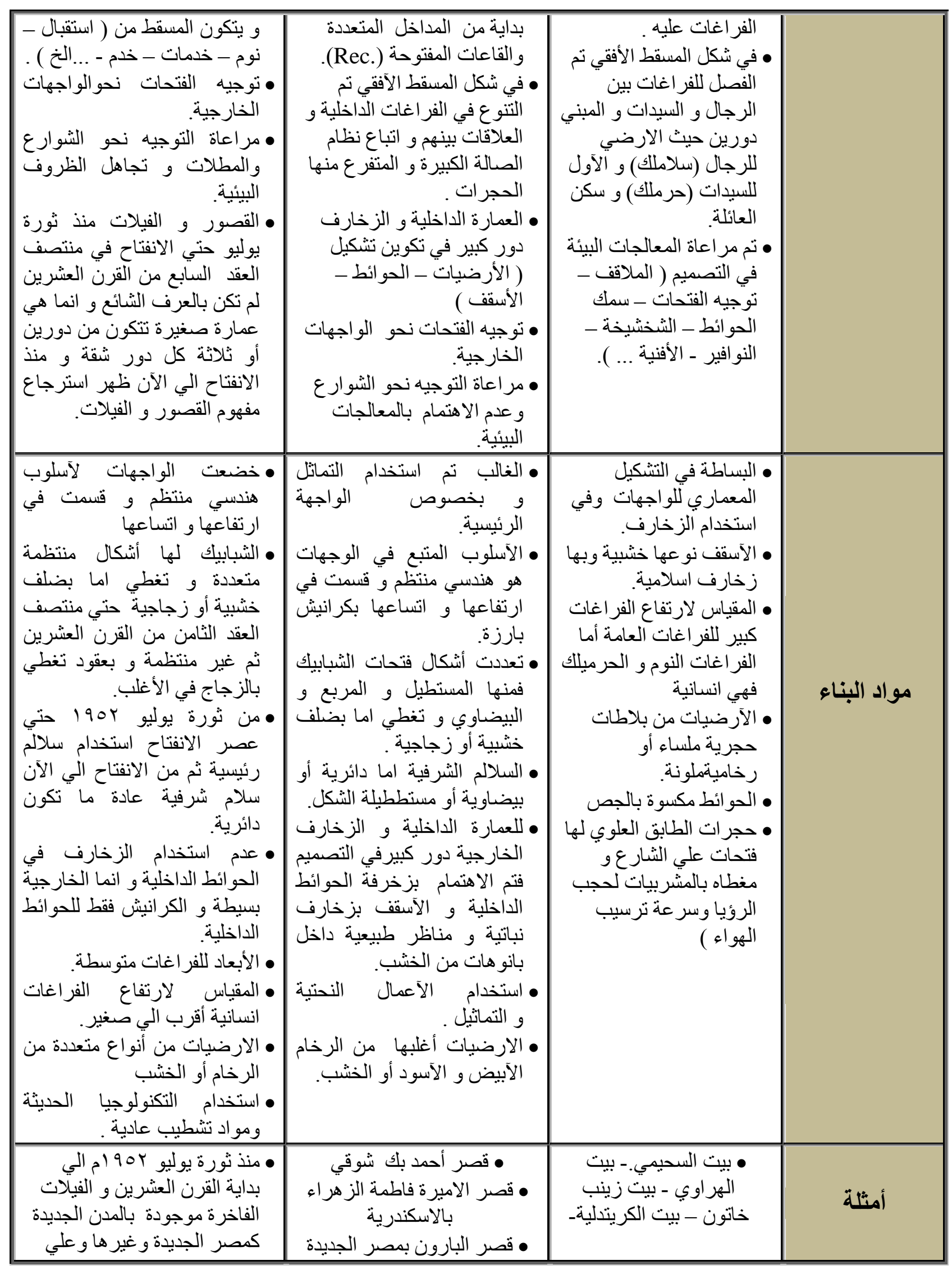




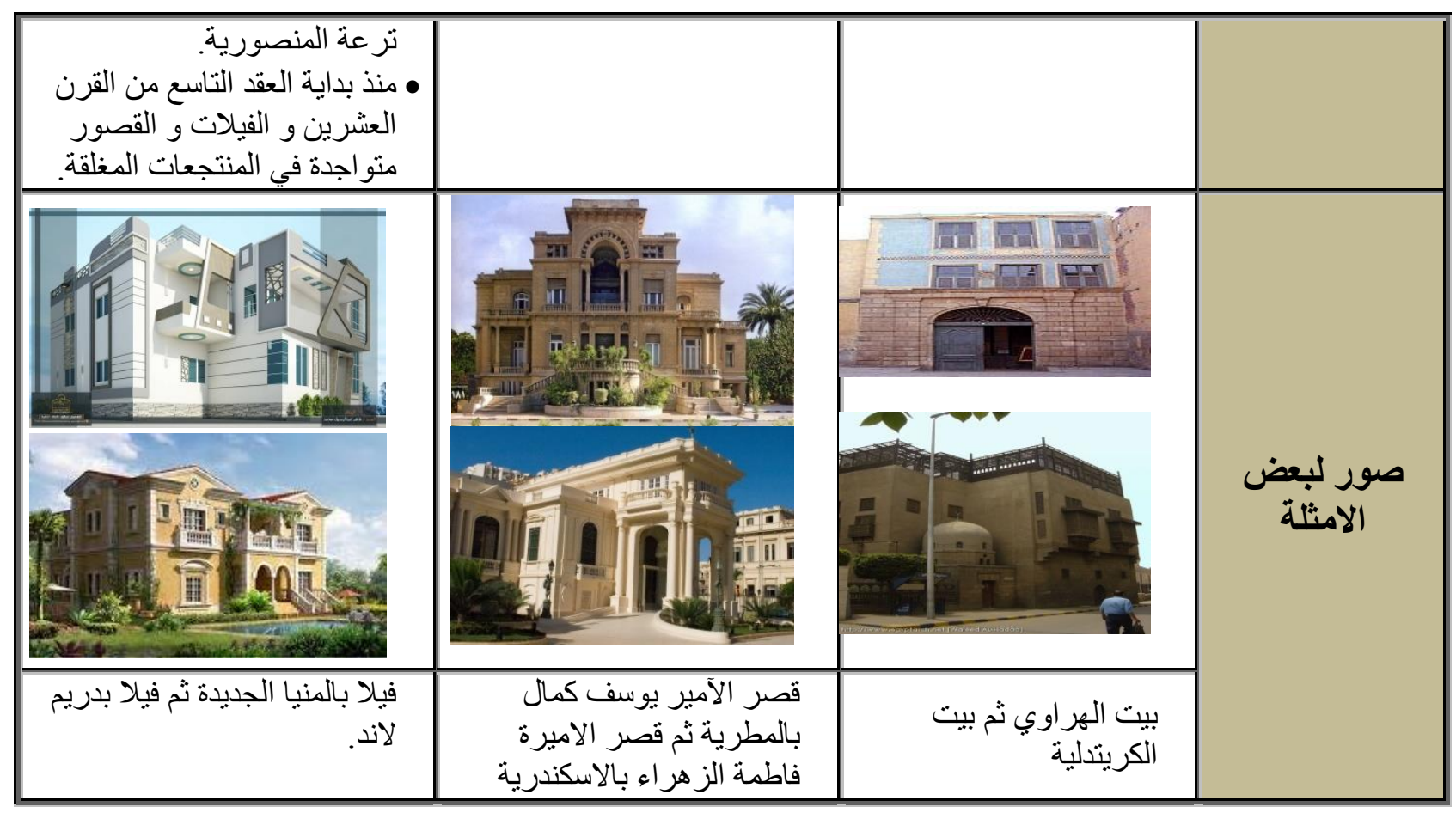

\section{ـ ـ أهم معوقات الحفاظ علي المباني التراثية :

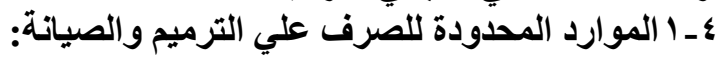

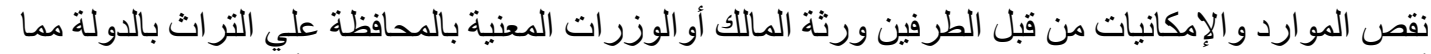

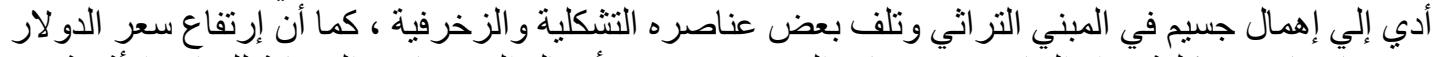

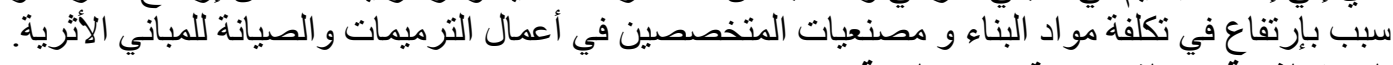

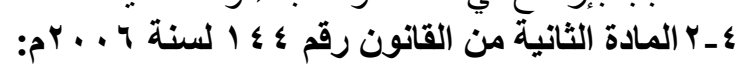

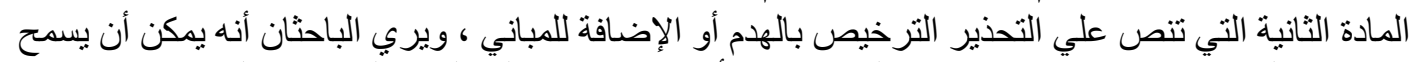

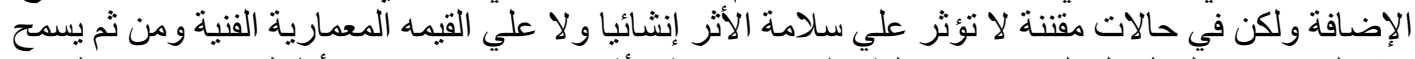

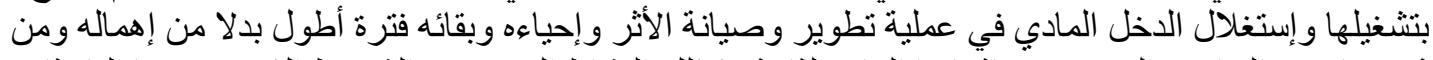

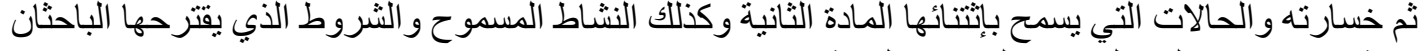
هم ثلاث حالات ،الجدول ـr بالات (المصدر :الباحثان). جدول ج الحالات التى يسمح باستثانها المادة الثانية من القانون وكنلك النثاط المسموح و الثروط التى يقتحها الباحثان

\begin{tabular}{|c|c|c|}
\hline النشاط الذي يسمح به & الحالات التي يسمح فيها & \\
\hline 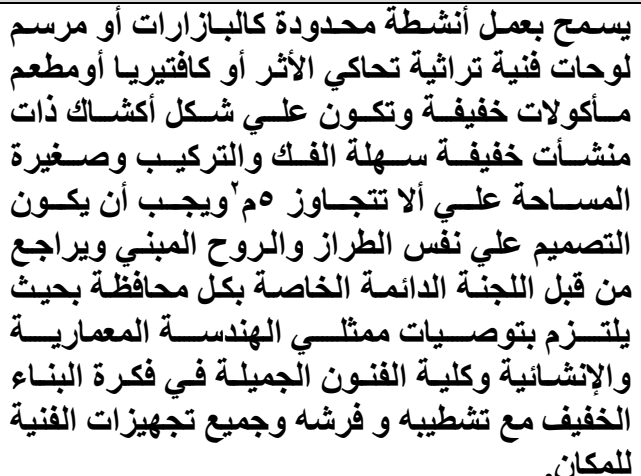 & في حالة وجود حليقة ملحقة بالمبني الأثري & 1 \\
\hline
\end{tabular}




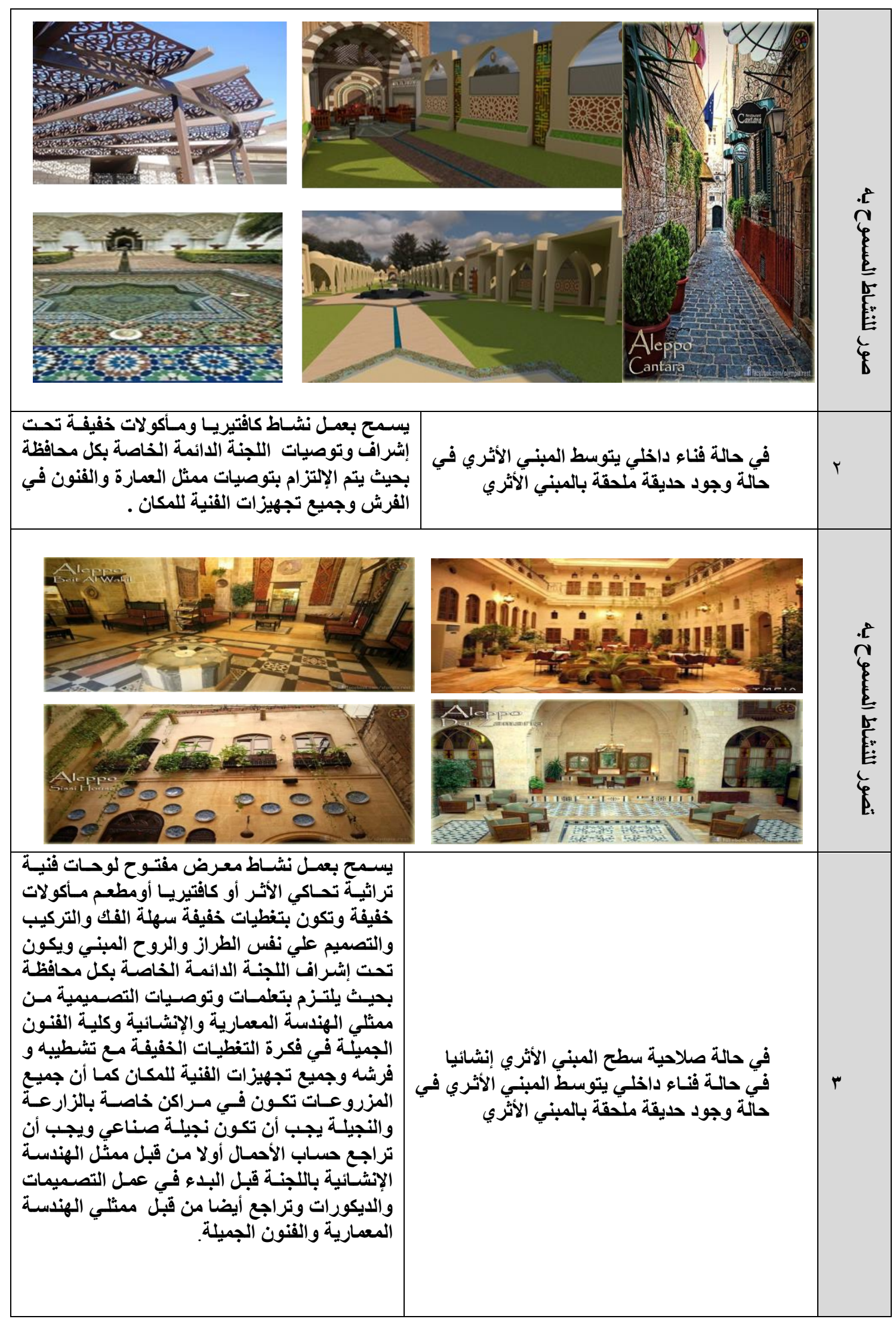



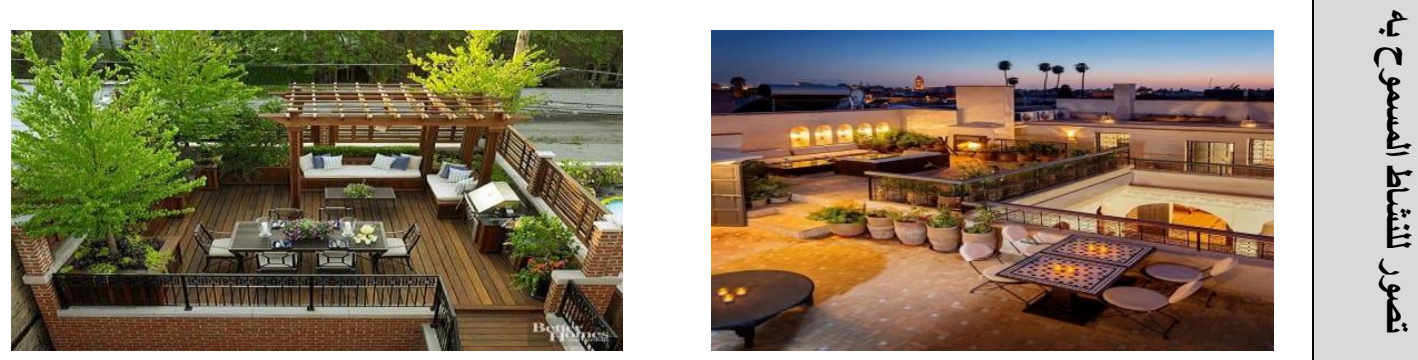

ع ـ ت تلاعب بعض الملاك وظهور الحيل الملتويـة:

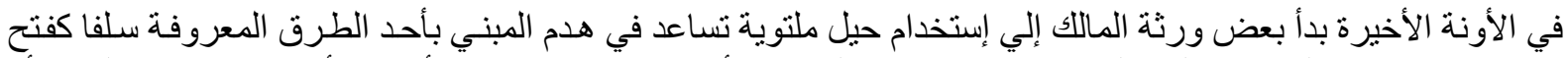

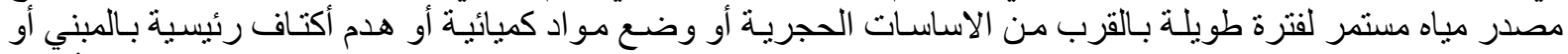

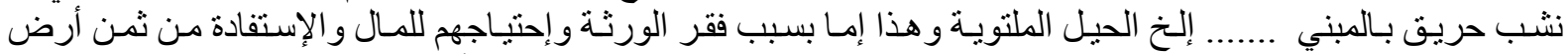

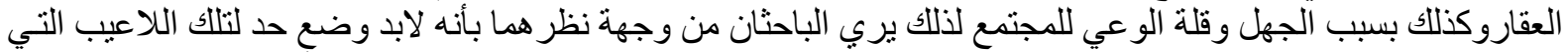

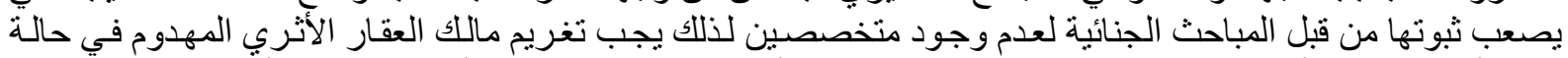

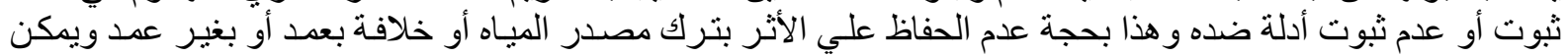

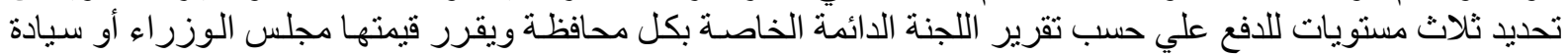

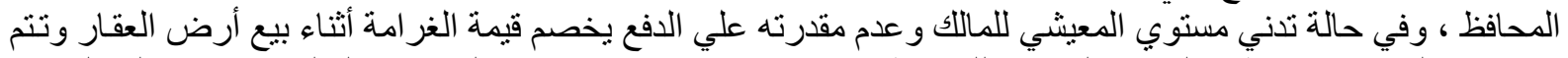

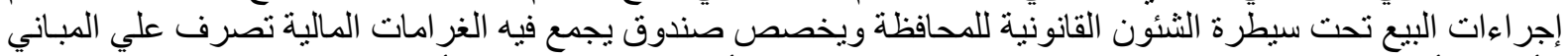

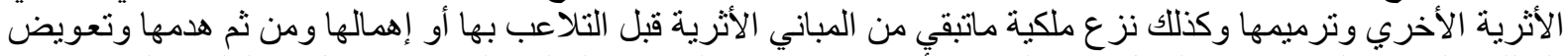

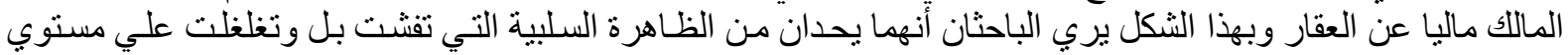

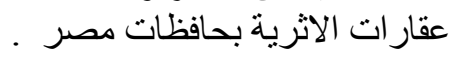

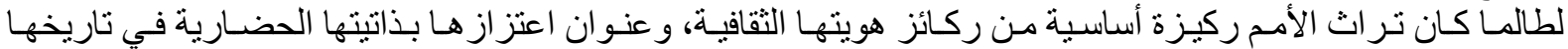

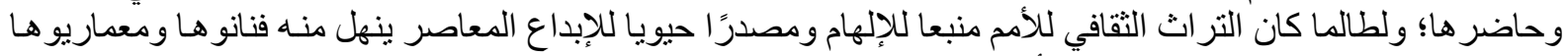

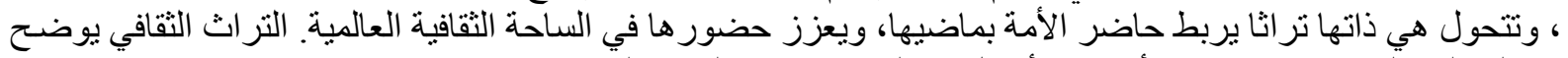

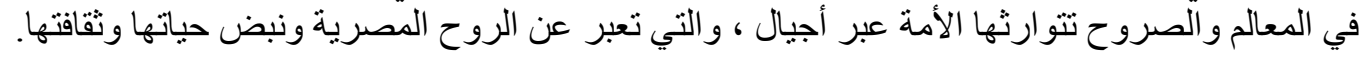

هـ الأهداف المرجوة من الحالات التي يسمح بإثتنائها المادة الثانية من القانون ؛ ؛ أل من وجهة نظر الباحثان:-

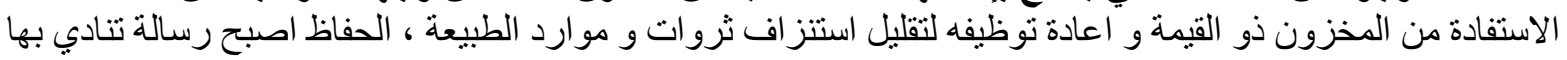

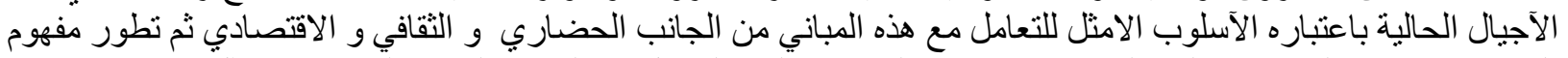

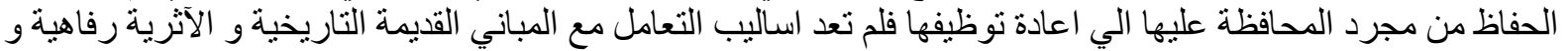

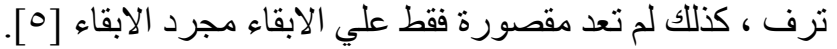

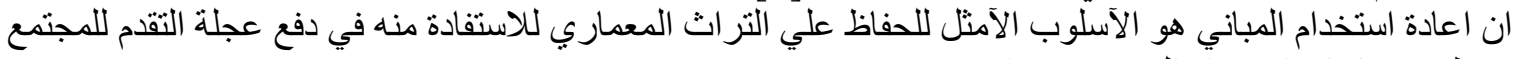

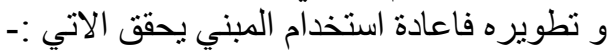

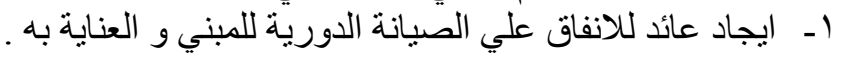

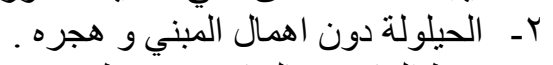
r- بـ ربط الماضي بالحاضر عن طريق فتح القصور القديمة للجمهور في استخدامات عامة تناسب تللك القصور .

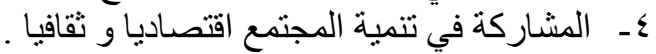

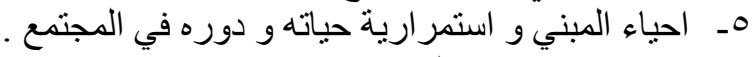

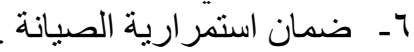

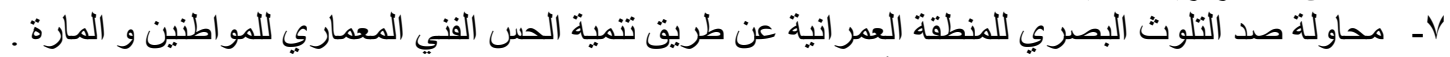

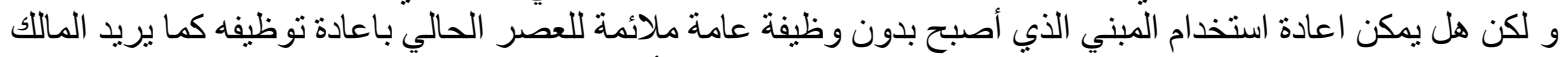

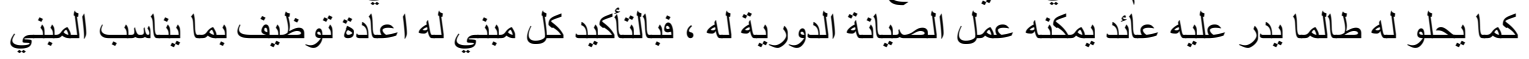


و الفر اغات و العناصر و المفردات المعمارية و بما يضمن تقليل اهلاكه عن طريق الاستخدام الخاطئ كما سنري في الإني

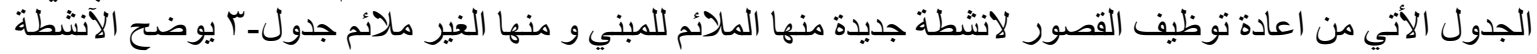
جدول r أمثلة لقصور تراثية تم تحويلها لكى تثظل أنثطة متنوعة .

المناسبة للقصور القديمة و التاريخية [9]

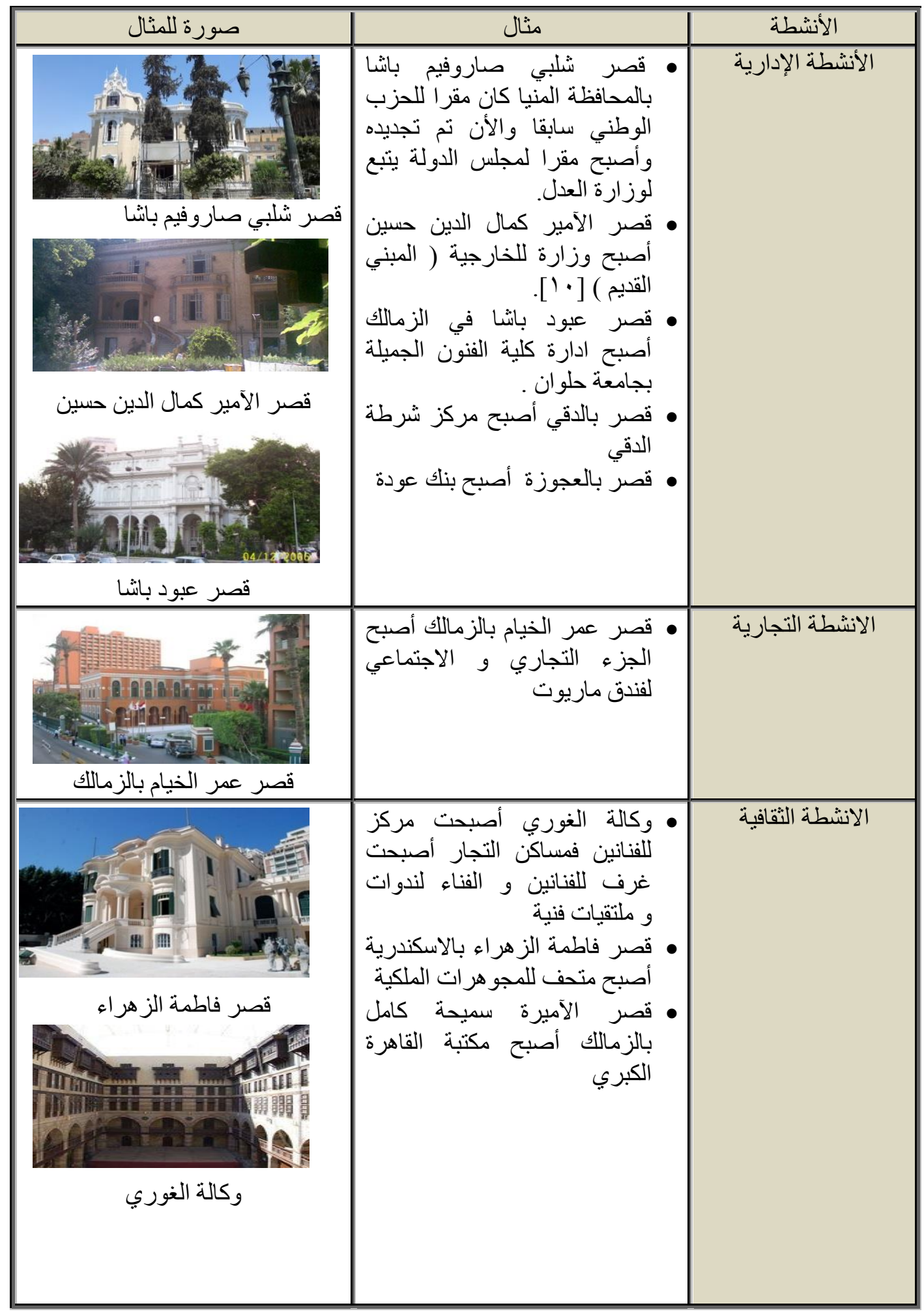




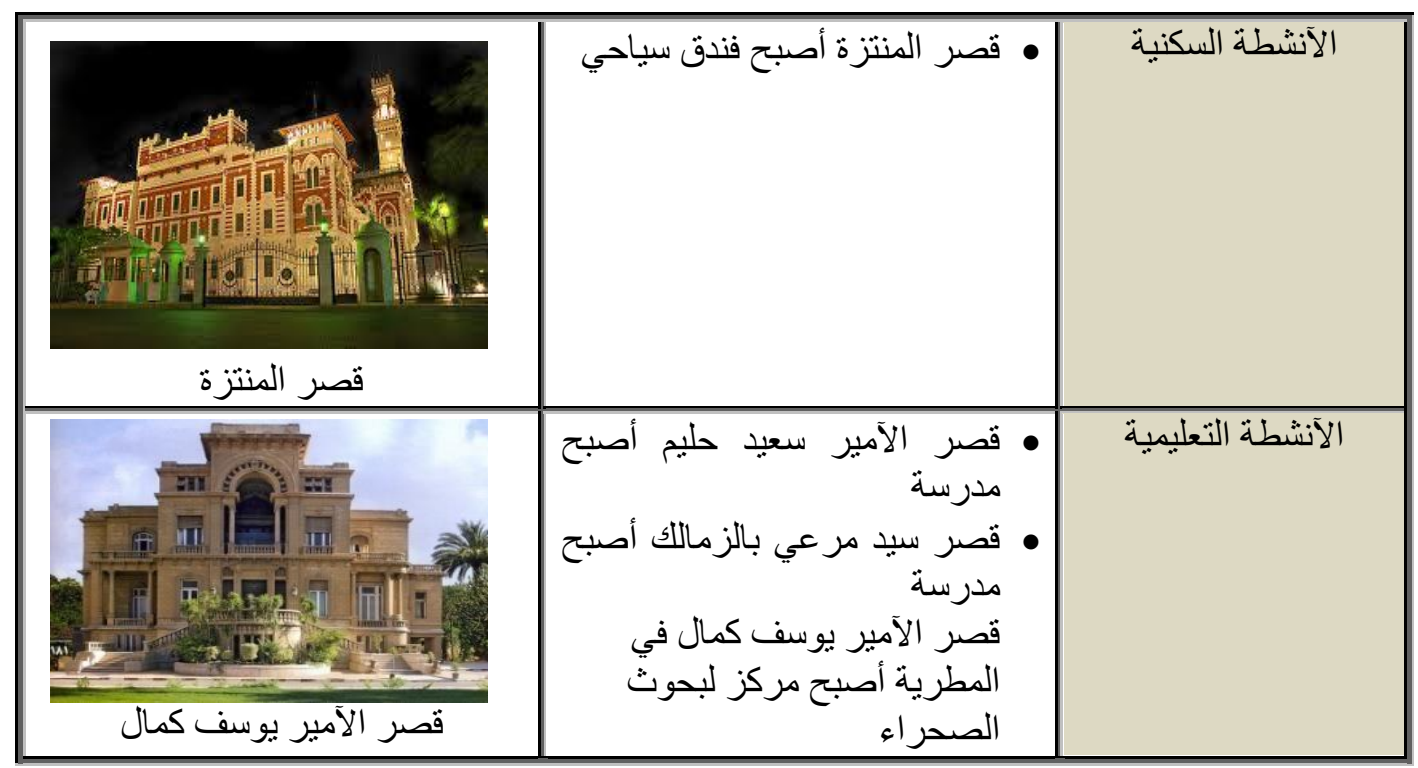

آـالعوامل المؤثرة علي اعادة التوظيف :-

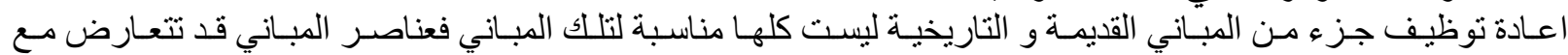

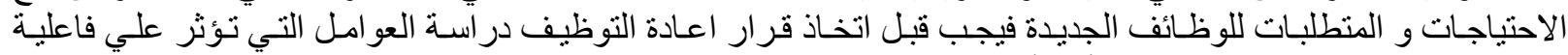

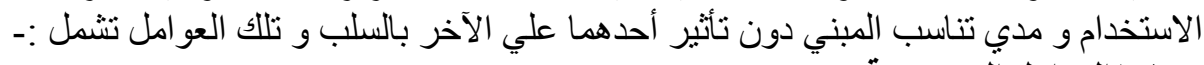

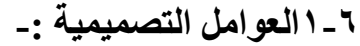

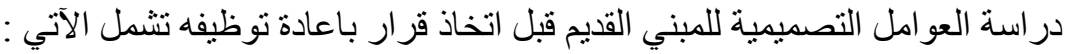

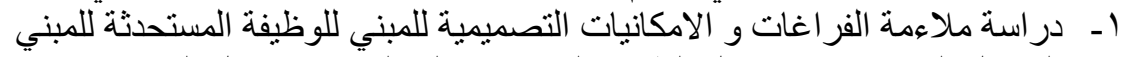

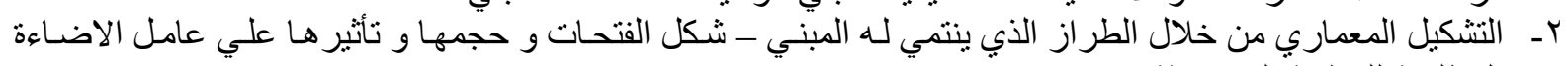

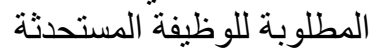

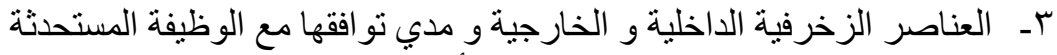

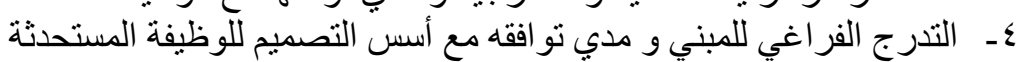

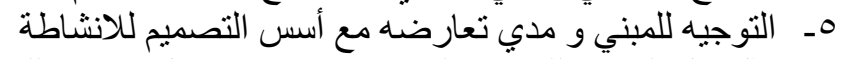

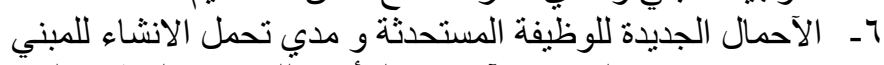

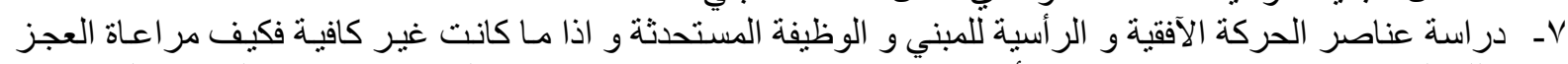
بتلك العناصر و توفير ها بدون اظهار أنها عناصر مستحدثة و نراعي في ذات الوفية الوقت احتياجات الوظيفة المستحدثة

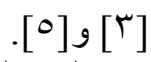

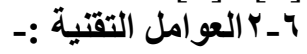

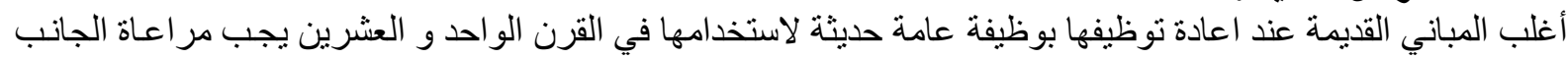

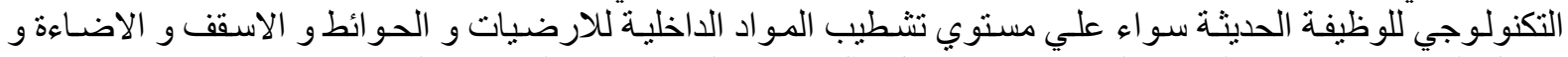

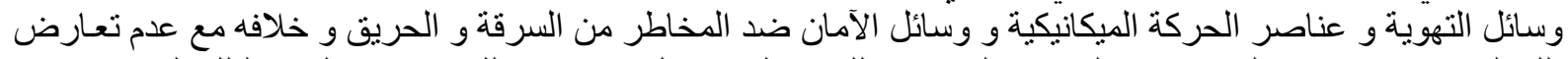

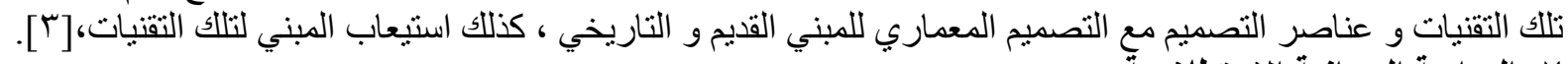

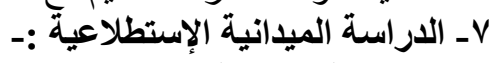

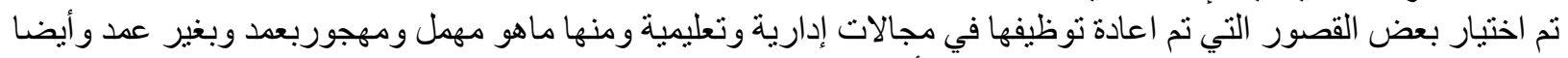

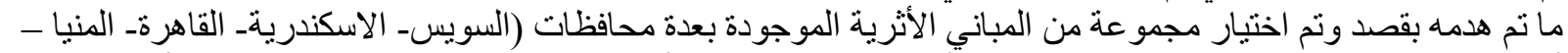

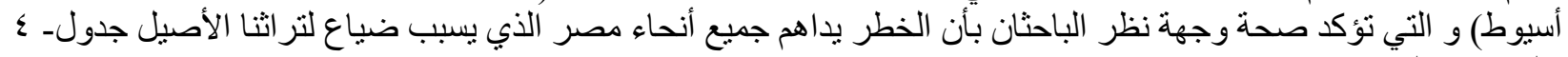
(المصدر :البآحثان) (ولئ 
جدول ؛ ـ أمثلة الدراسة الميدانية الاستطلاعية التى تؤكد وجهة نظر الباحثان

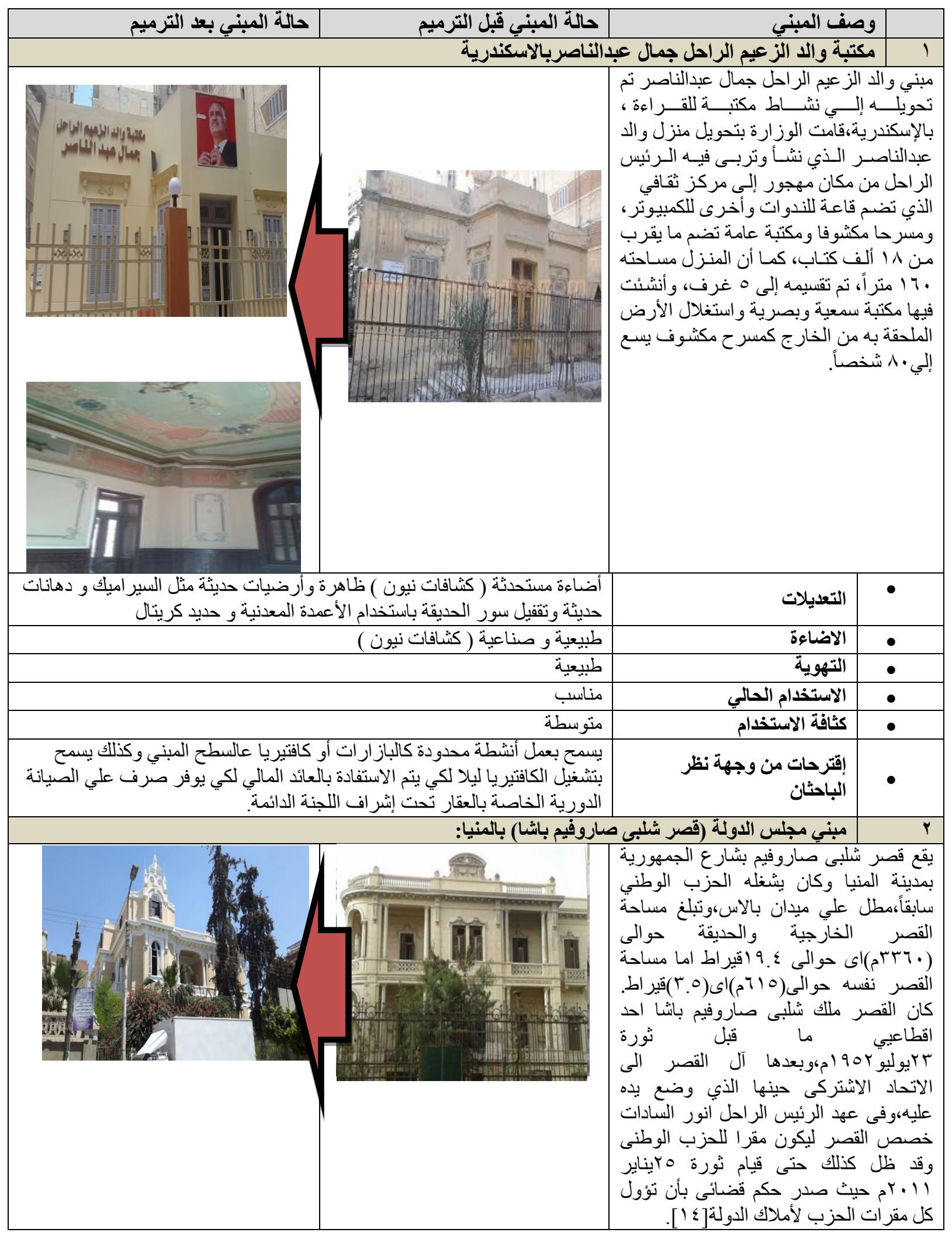




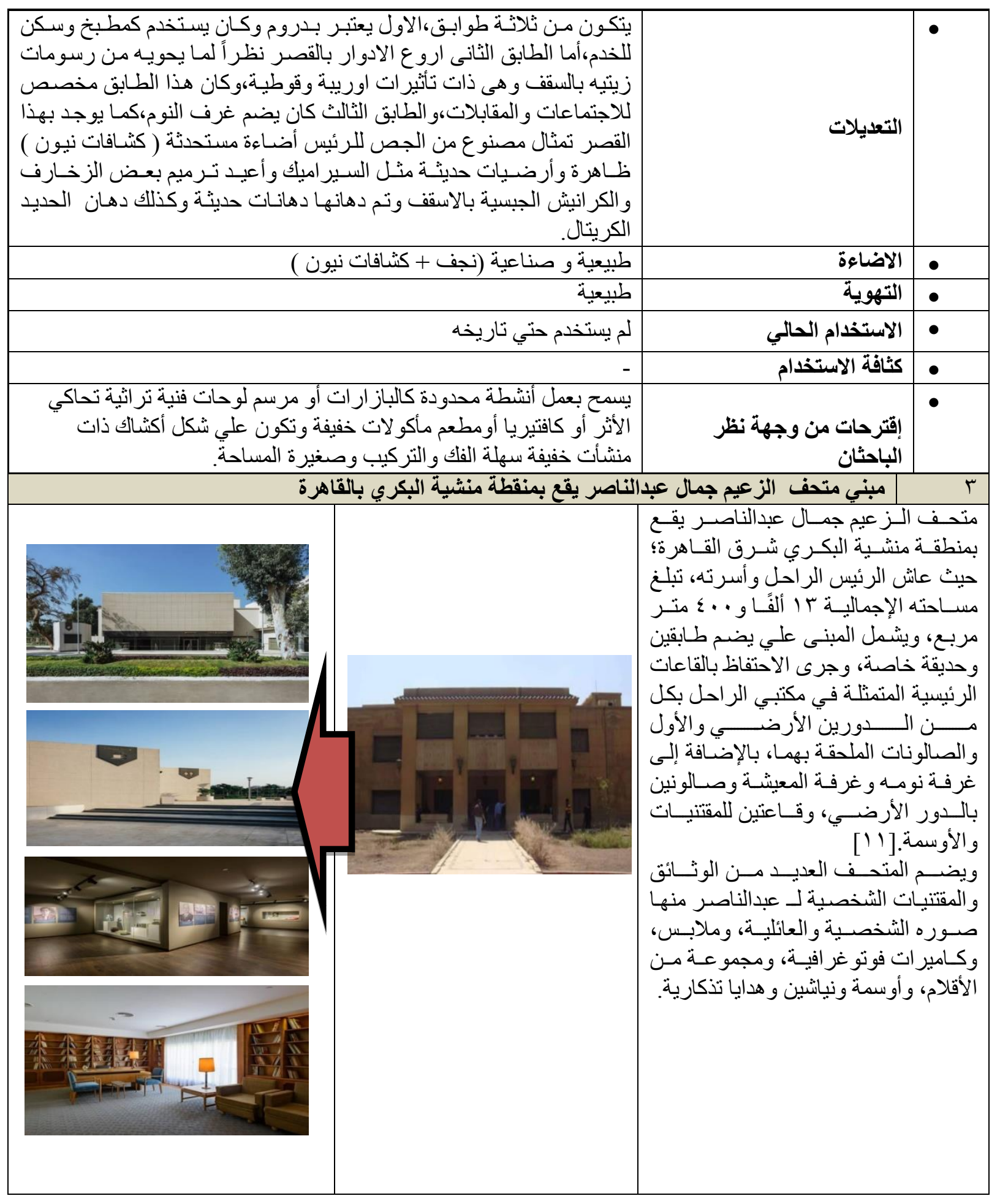




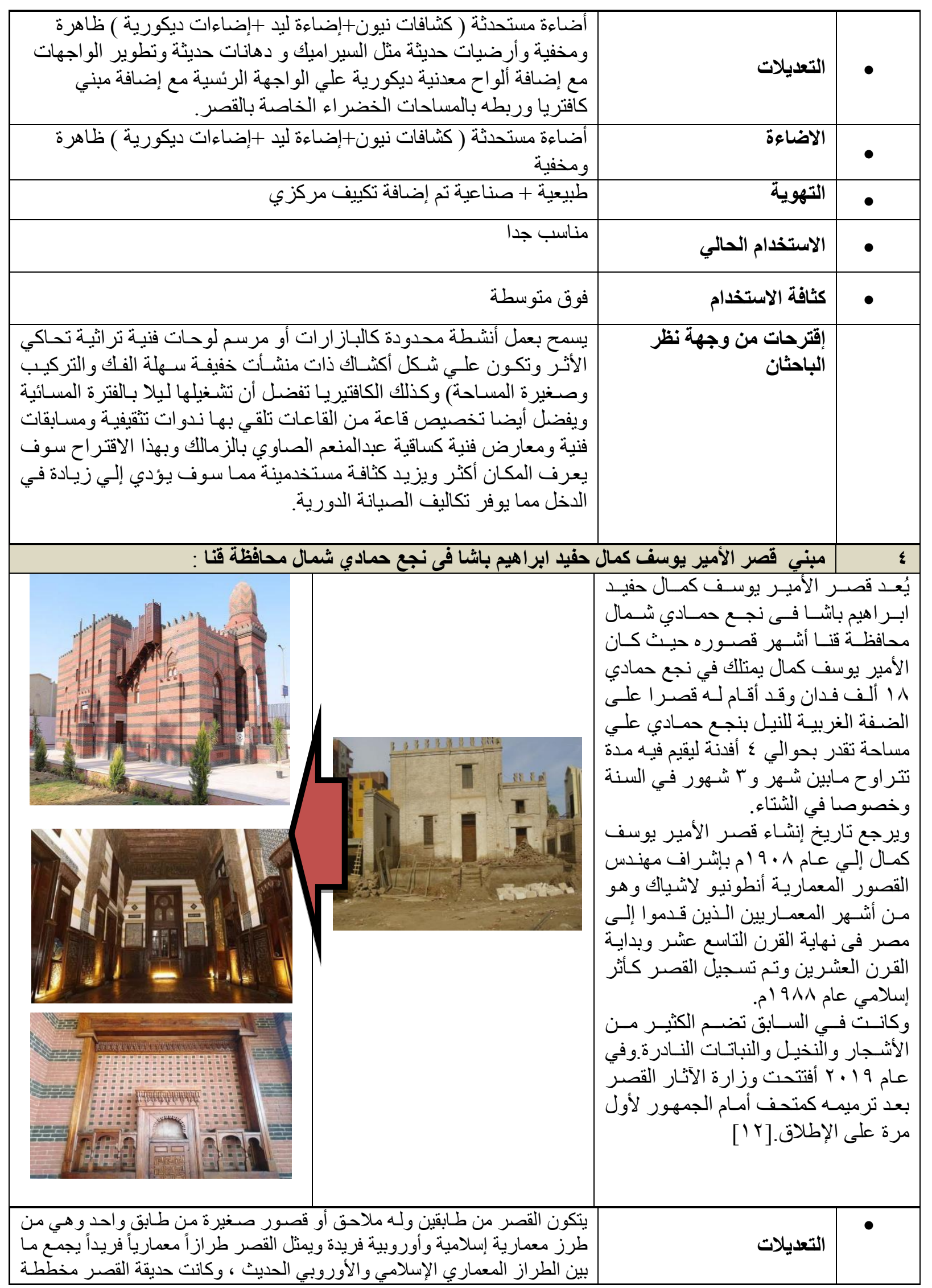




\begin{tabular}{|c|c|}
\hline \multicolumn{2}{|l|}{ 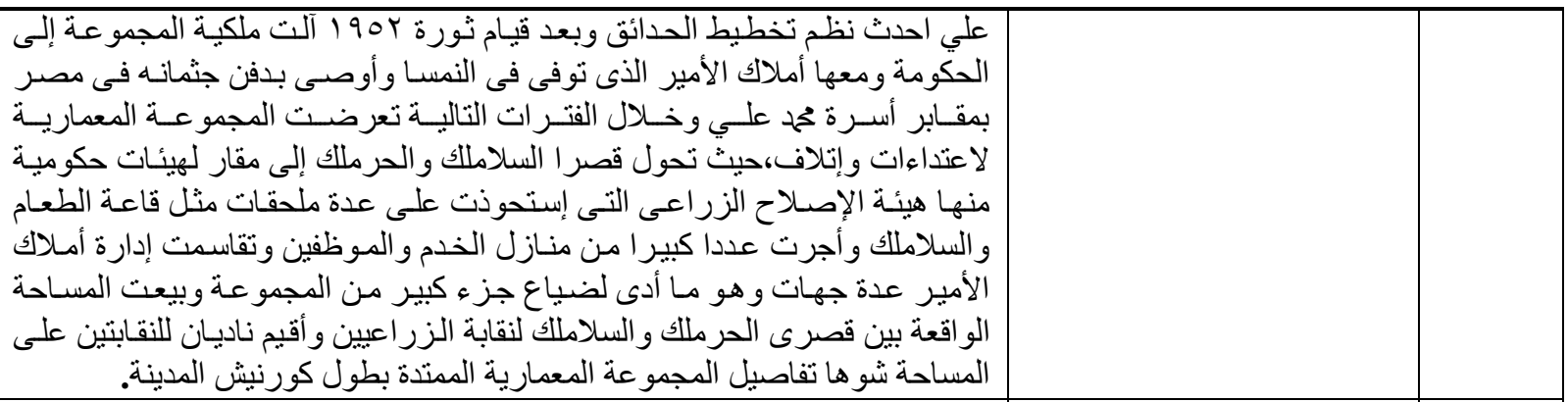 } \\
\hline طبيعية + أضاءة مستحدثة ( كشافات نيون) & الاضاءة \\
\hline طبيعية & التهوية \\
\hline متحف & \\
\hline متوسطة & كثافة الاستخدام \\
\hline 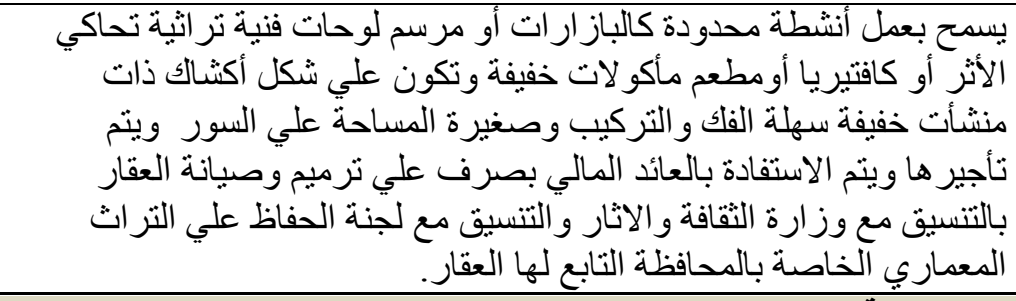 & إقترحثات من وجهة نظر \\
\hline \multicolumn{2}{|c|}{ • 1 مبني مكتبة مبارك (قصر الطحاوي) بمدينة القاهرة : } \\
\hline L-4 & 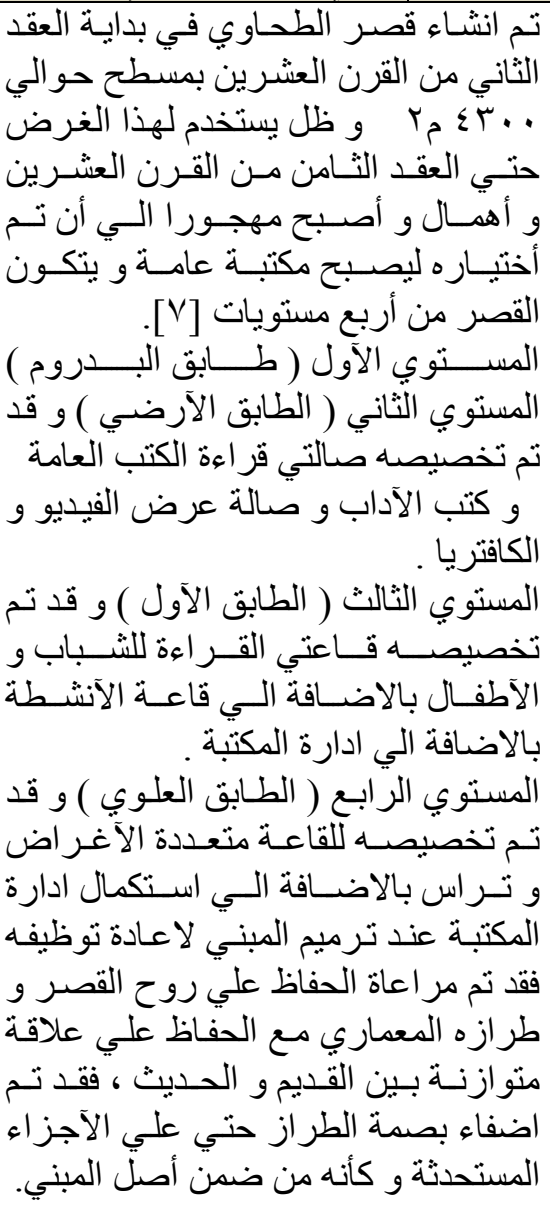 \\
\hline
\end{tabular}




\begin{tabular}{|c|c|c|}
\hline 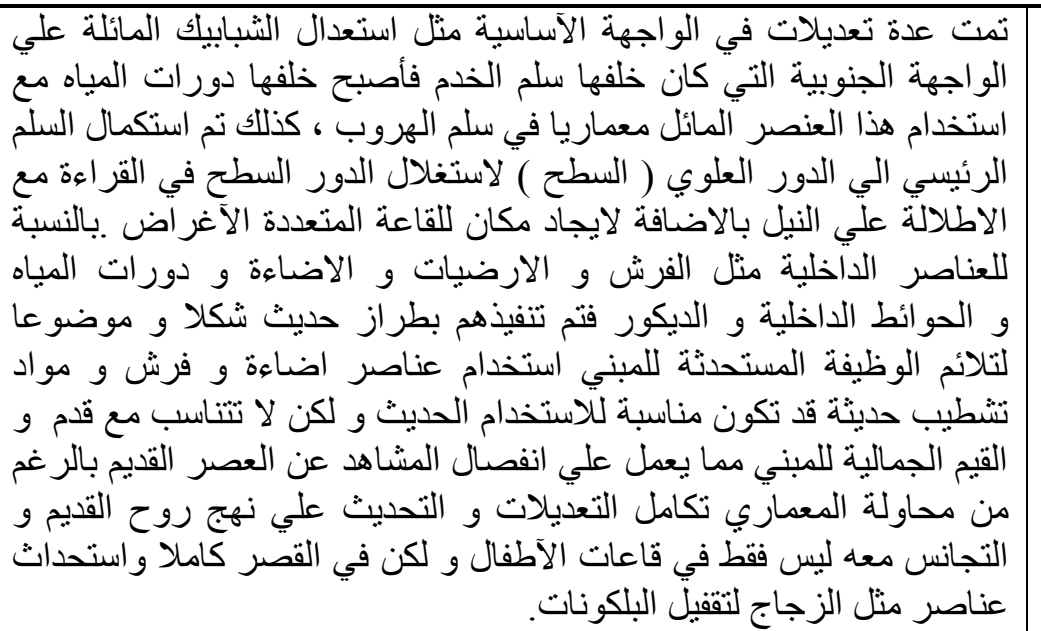 & التعديلات & • \\
\hline طبيعية و صناعية ( كثافات نيون ) & 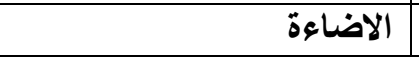 & • \\
\hline & 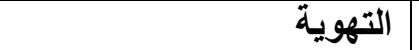 & • \\
\hline (2) & الاستخدام الحالي & - \\
\hline 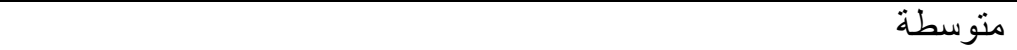 & كثافة الاستخدام & • \\
\hline 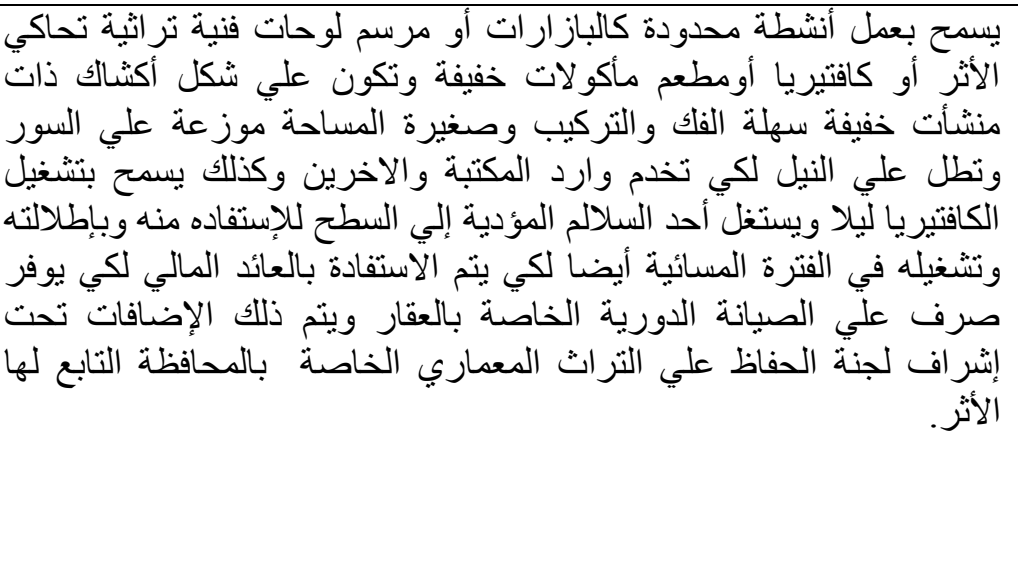 & إلباحثان & \\
\hline \multicolumn{2}{|c|}{ مبني قصر بشارة بمدينة أسيوط : } & 7 \\
\hline $\lim ^{2} \frac{3}{12}$ & 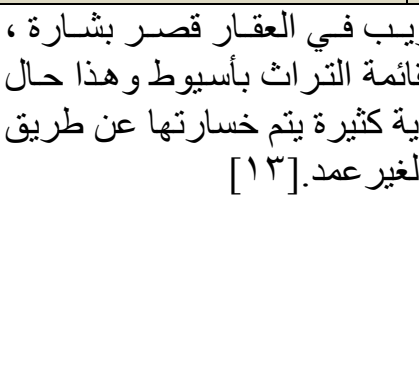 & \\
\hline
\end{tabular}




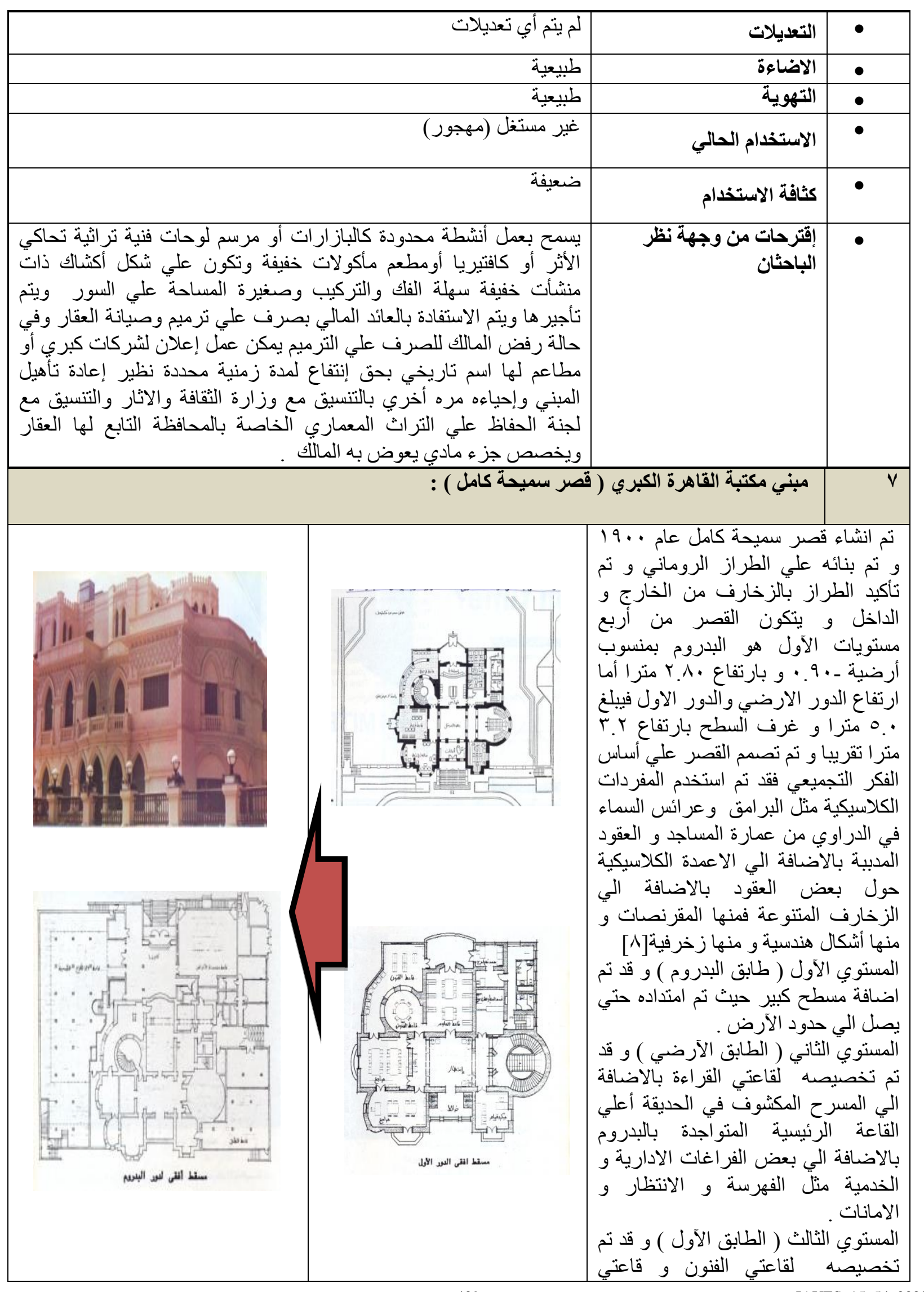




\begin{tabular}{|c|c|c|}
\hline 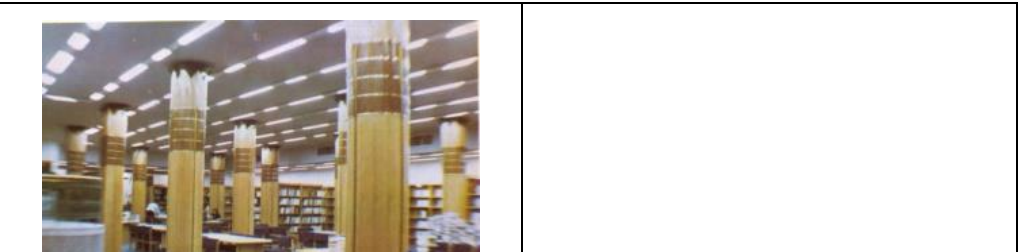 & \multicolumn{2}{|c|}{ 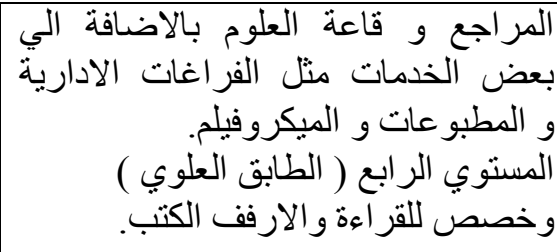 } \\
\hline 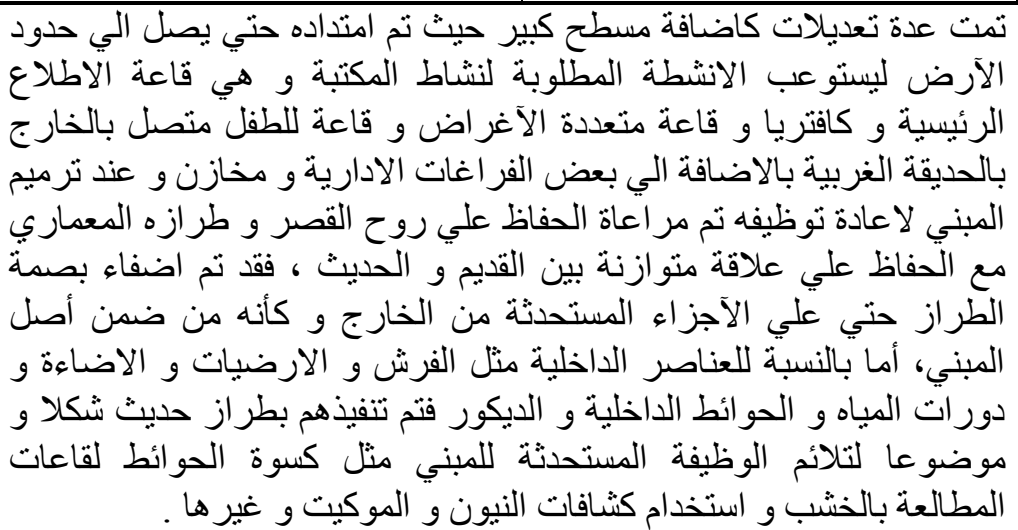 & التعديلات الت & $\bullet$ \\
\hline صناعية ( كثنافات نيون ) & 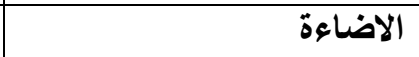 & • \\
\hline طبيعية وصناعية تم تركيب تكييف مركزي & التهوية & $\bullet$ \\
\hline مناسب & الاستخدام الحالي & \\
\hline منوسطة & كثافة الاستخدام & \\
\hline 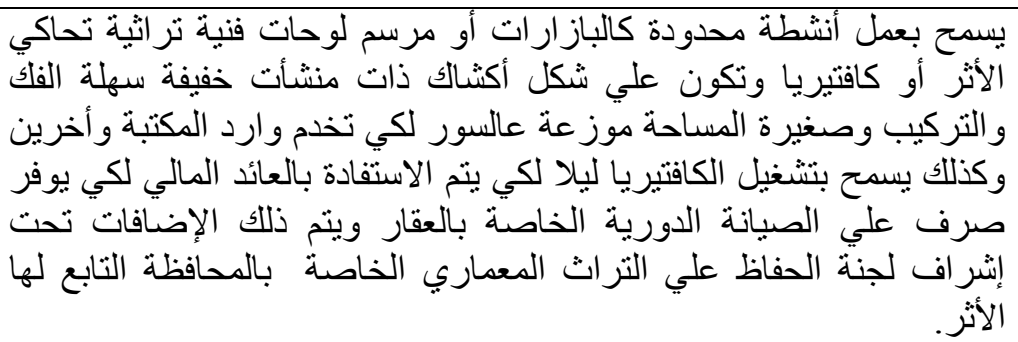 & إقباحثان & • \\
\hline : Monf & مبني وكالة مونفراتو (erato & $\Lambda$ \\
\hline 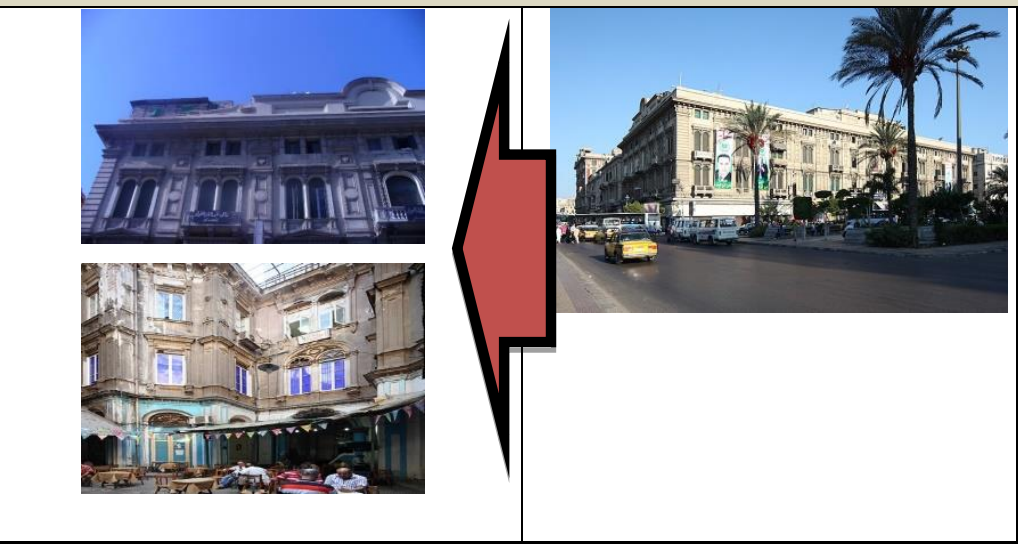 & 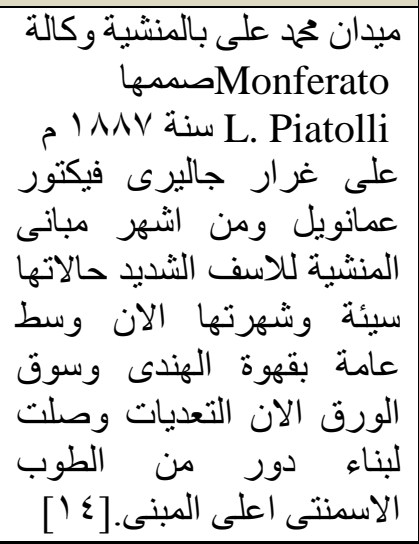 & \\
\hline 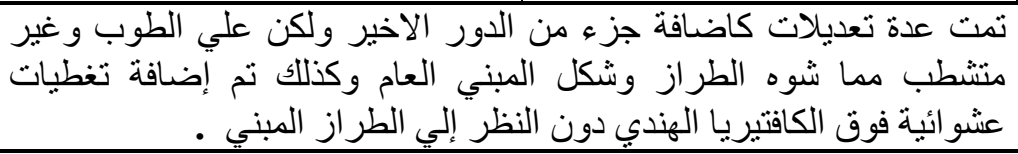 & 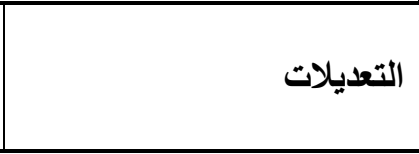 & \\
\hline
\end{tabular}




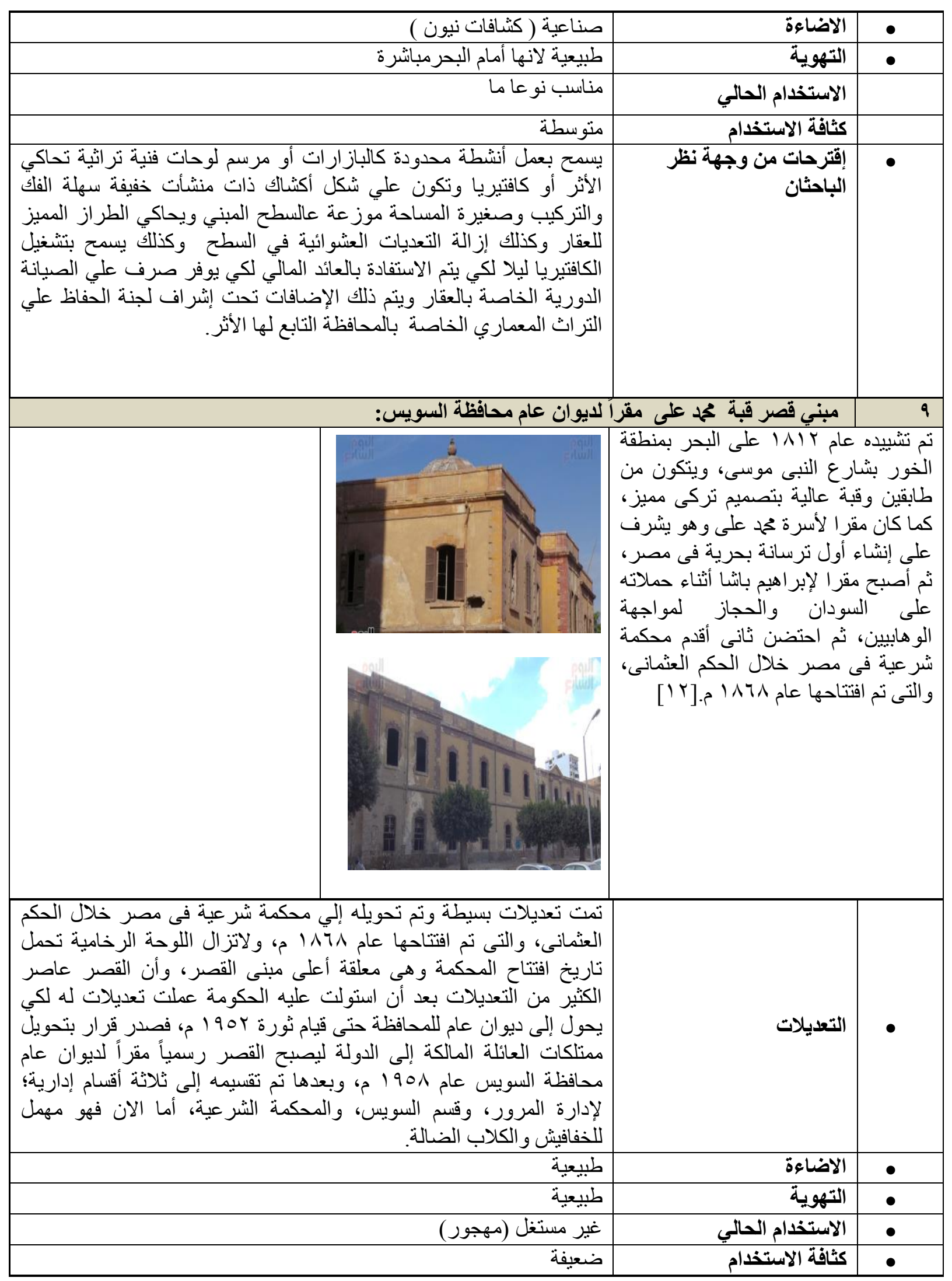




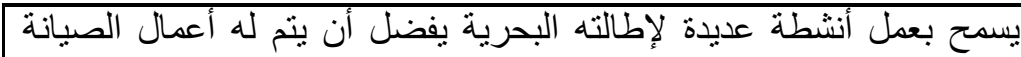

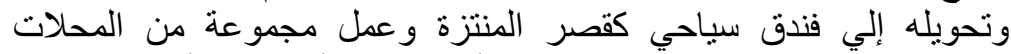
الصغيرة بالادور الارضي كالباز ارات أو كافتيريا أونيات أومطعم مأكولات خفيفة

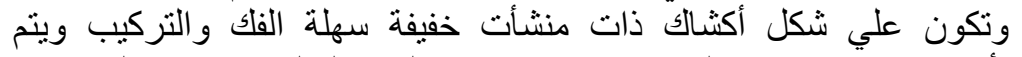

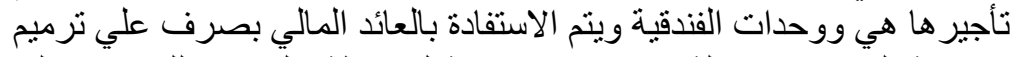

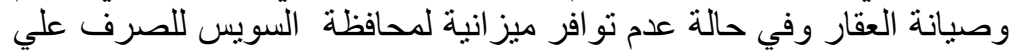

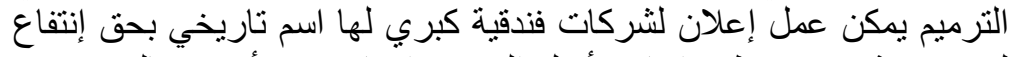

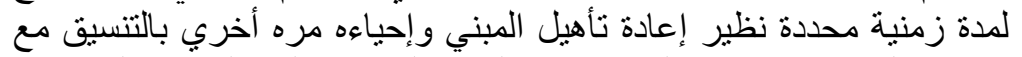

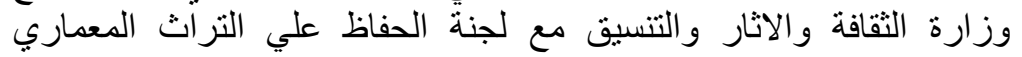

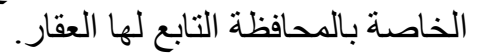

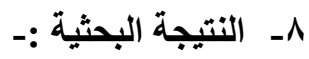

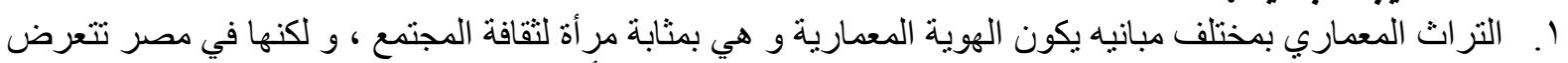

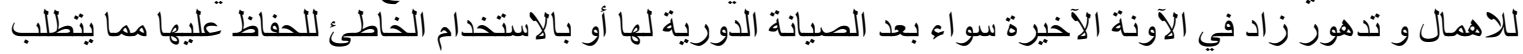

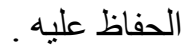

r. المباني و بالاخص المباني السكنية لعلية القوم تتبع الثقافة للمجتمع حتي عصر الاغتراب و هو حكم حمحيد علي الذي بدأ

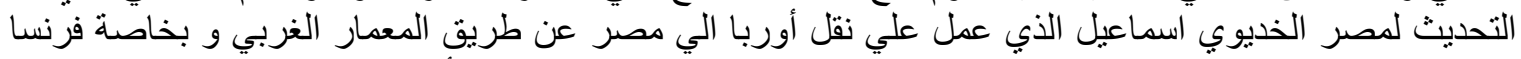

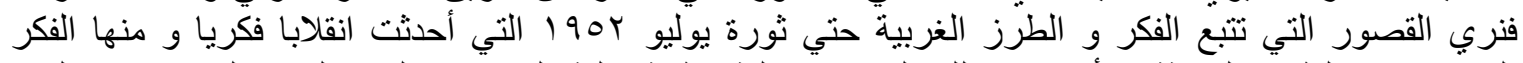

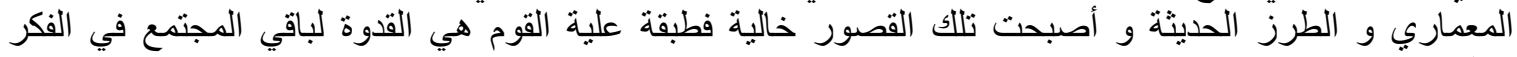
و المعمار و خلافه.

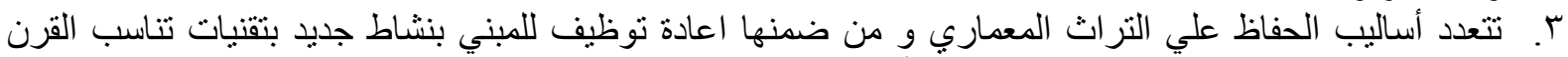

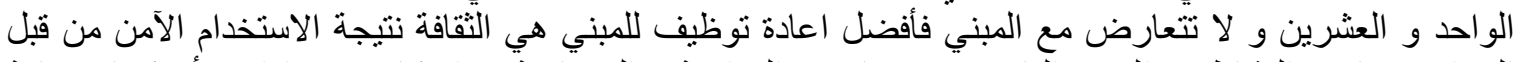

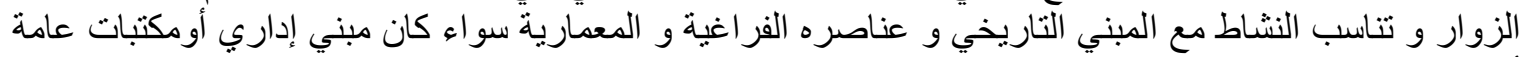

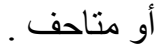

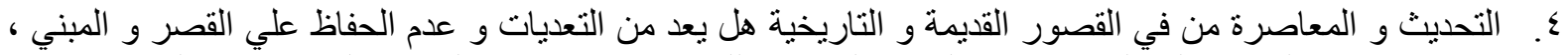

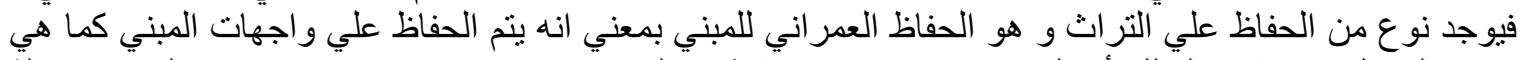

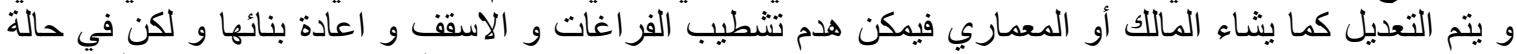

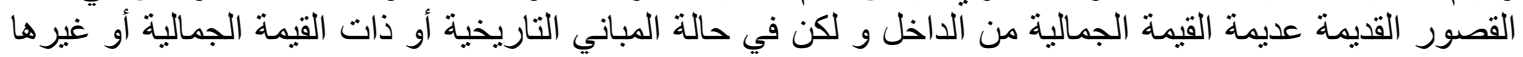

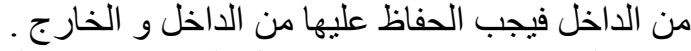

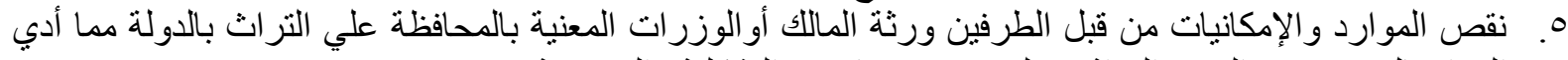

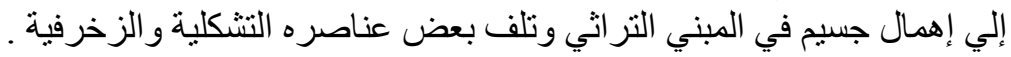

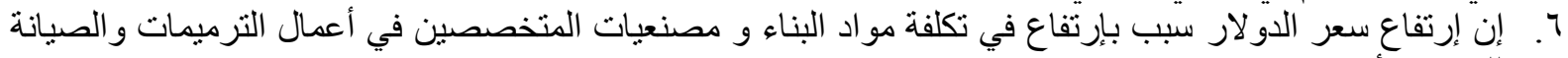
للمباني الأثرية.

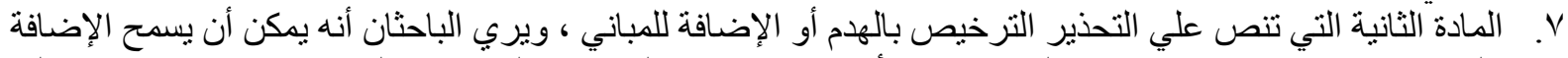

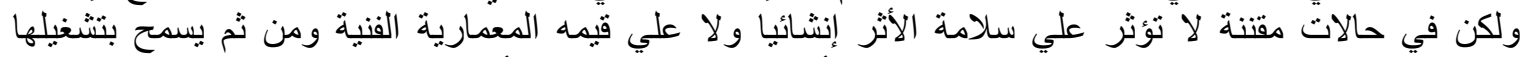

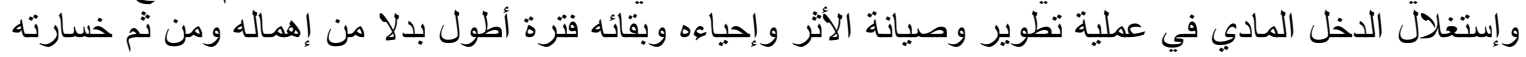

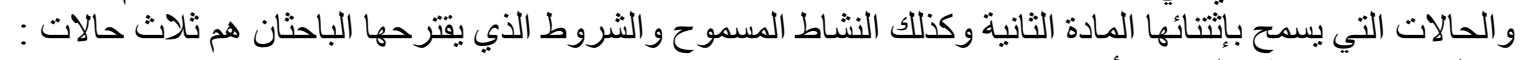
- في حالة صلاحية سطح المبني الأثري إنشائيا.

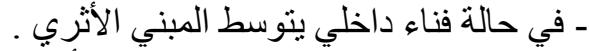
- في حالة وجود حديقة ملحقة بالمبني الأثري.

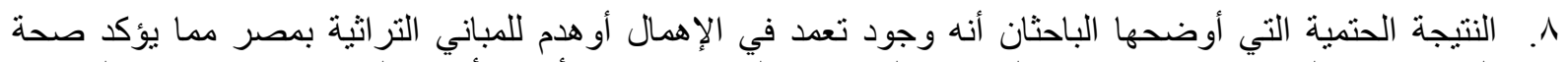

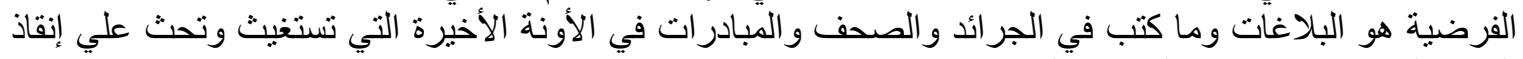

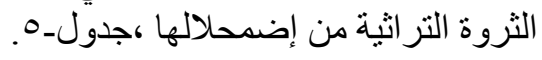


جدول ه ـ مظاهر التخريب ومناداة الأعلام بها وللبلاغات والتى تؤكد وجهة نضر الباحثان

هـ تراث الإسكندرية يتعرض للانهيار.. ومبادرة لإنقاذ ما يمكن إنقاذه

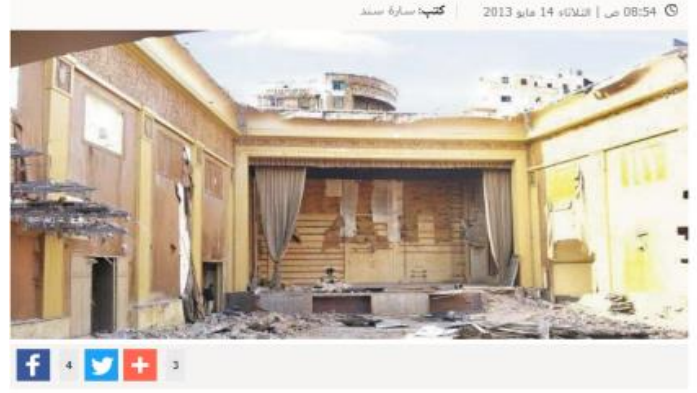

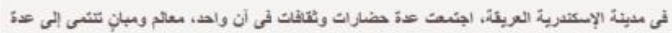

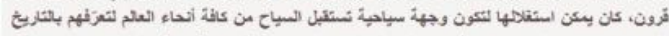

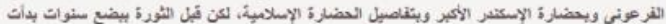

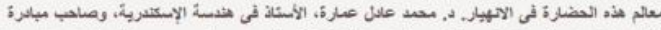

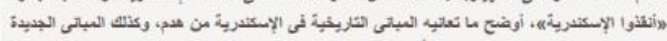

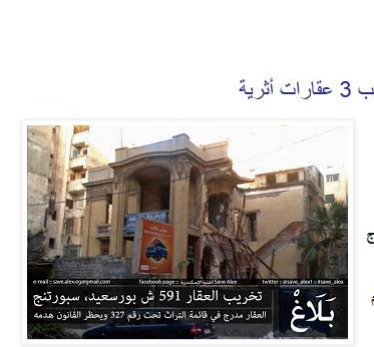

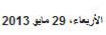
"أنقذوا الإسكندرية"

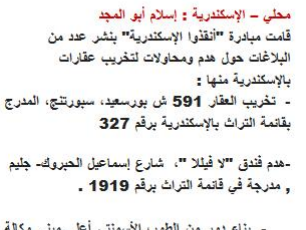

بناء دود من الطوب الأسمنتي أعى مبنى وكالمة

ميدان محثد طن بالمنثية.

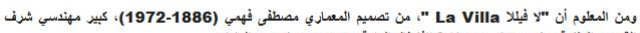

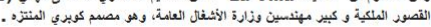

والفيلا تم تميمها بشكل رانع منذ القل من سنتين وتم تحويلها إلى فندق Boutique Hotel ، وهي تجربة راندة .
الهدم ينال "قصر بشارة" التاريخي بأسيوط
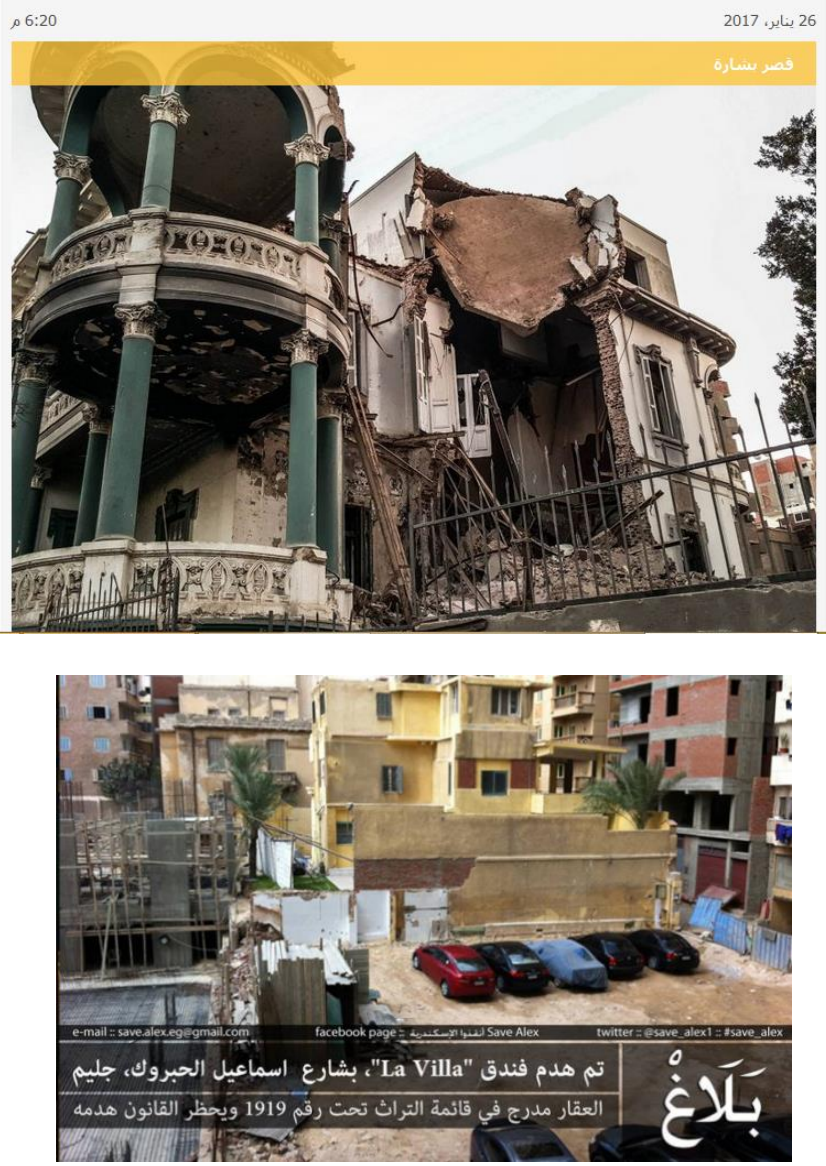

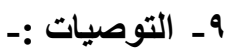

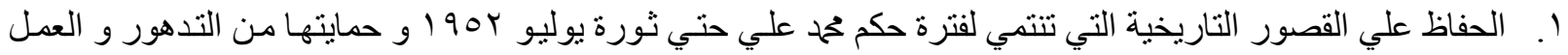

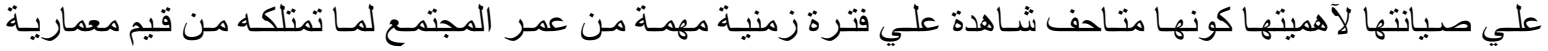
و جمالية و تاريخية

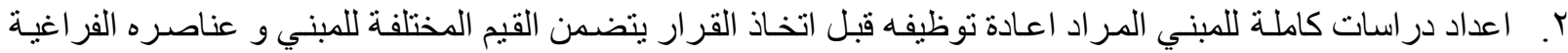

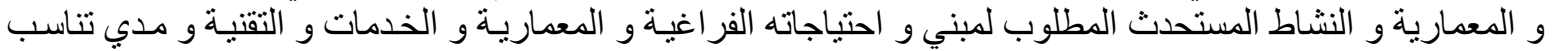

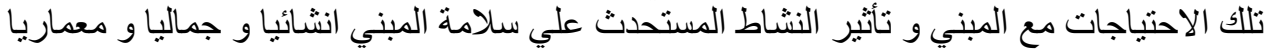

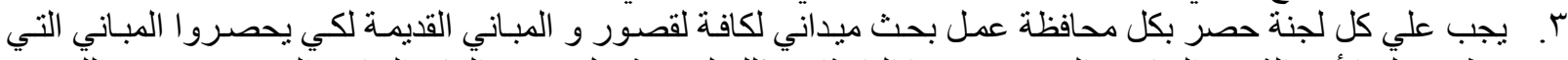
تنطبق علَيها أحد الثلاث الحالات التي وصي بها الباحثان وذللك لسر عة حل وجود الَّائد المـادي ألسريع وتوفيره للتّرميم و الصبانة .

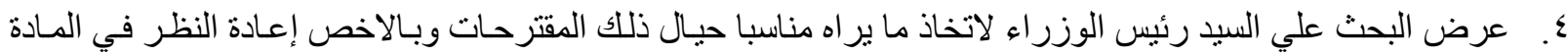

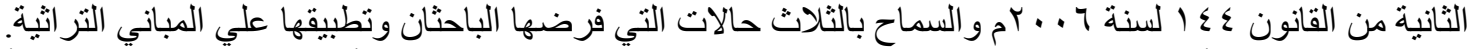

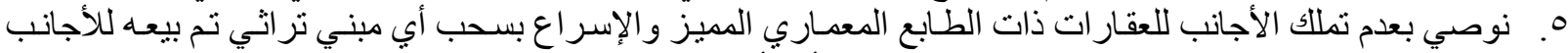

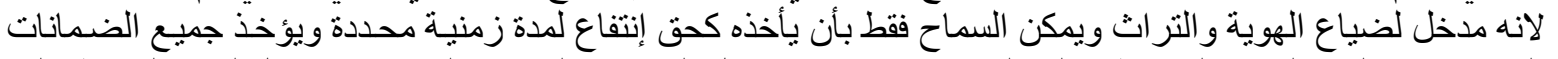

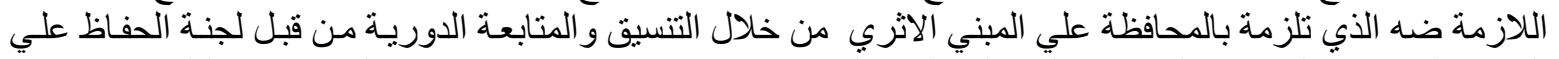

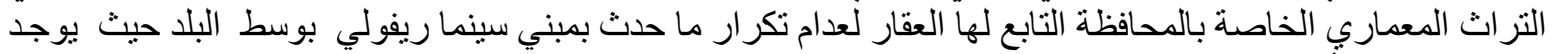

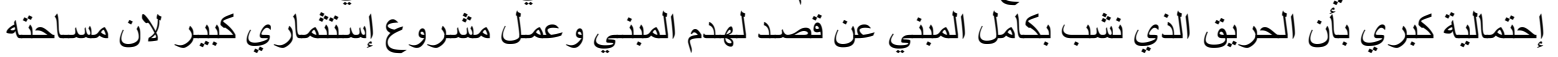


كبيرة جدا وخاصة أن المالك أحد الامر اء السعوديين الذي ليس له و لاء لتر اثناو هويتنا لذلك يجب أن تقرر وزارة الثقافة

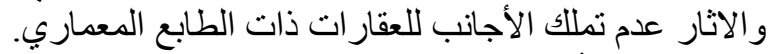

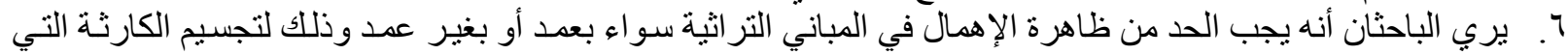

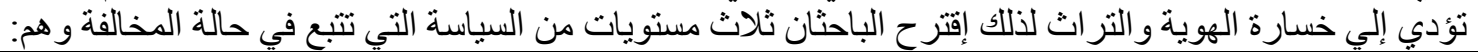

\begin{tabular}{|c|c|c|c|}
\hline العقوبة من وجهة نظر الباحثان & المستوي & الحالة & \\
\hline 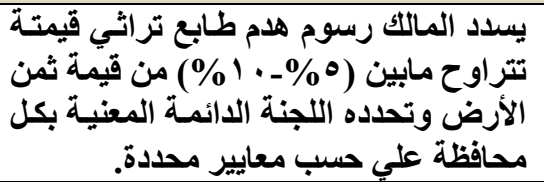 & $\begin{aligned} \text { (A) } \\
\text { (A) المستوي الأول }\end{aligned}$ & 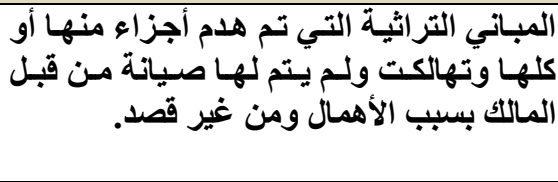 & 1 \\
\hline 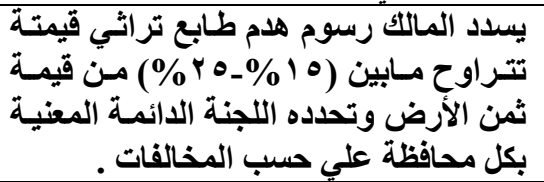 & $\begin{aligned} \text { (B) } \\
\text { (B) }\end{aligned}$ & 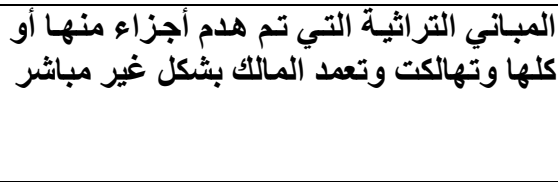 & $r$ \\
\hline 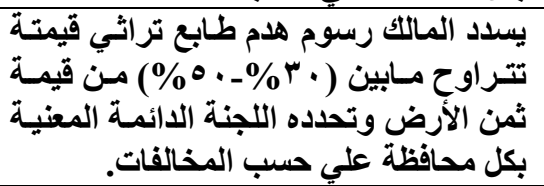 & $\begin{aligned} \text { المستوي الأول } \\
\text { (C) }\end{aligned}$ & 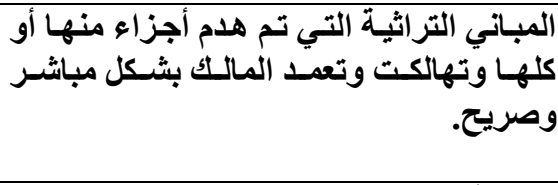 & $r$ \\
\hline
\end{tabular}

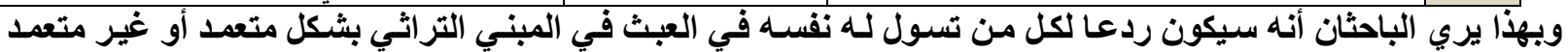

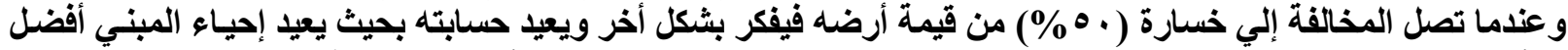

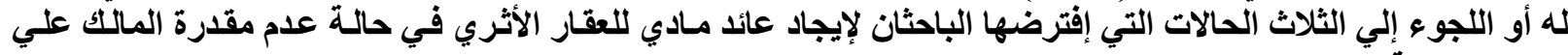
ترميم وصيانة عقاره.

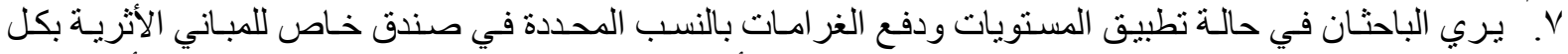

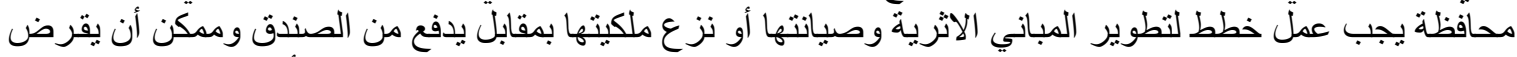

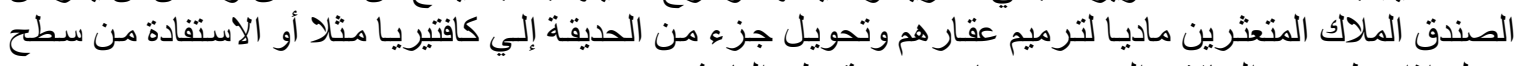

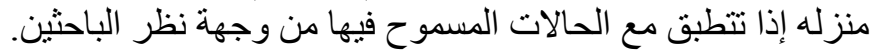

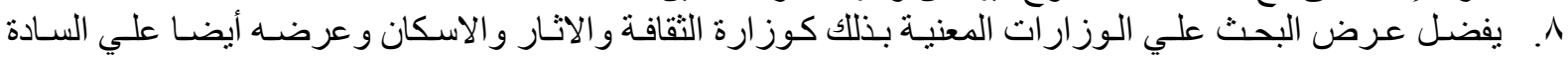
المحافظين. 9. الحالات الثناثة التي يطالب الباحثنان بنطبيقها وتعديلها من المـادة الثانيـة من القانون وكذلك الانثطة التي يسمح بها

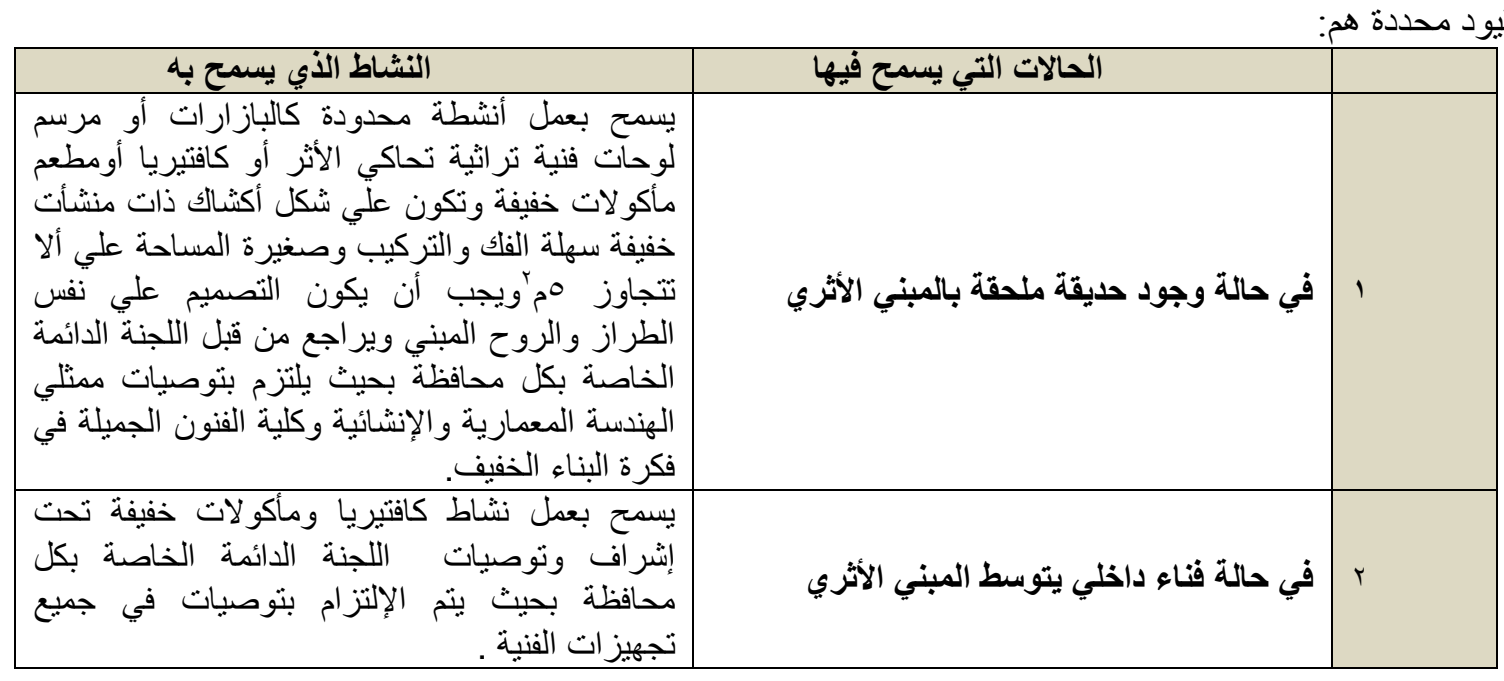


يسمح بعمل نشاط معرض مفتوح لوحات فنية تز اثية الواتية

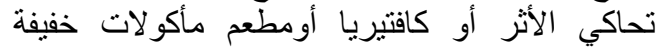

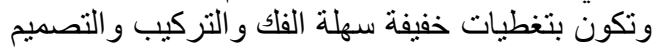

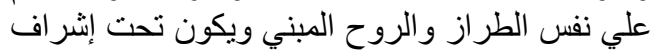

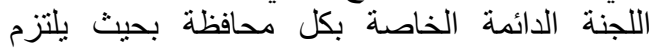
بتعلمات وتوصيات التصميمية في فكرة فئة فئة التغطيات

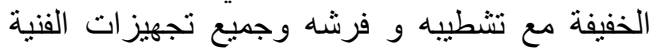

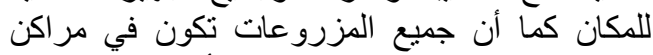

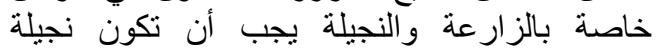

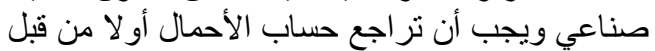

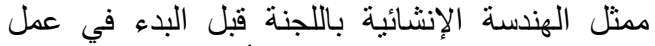
التصميمات و الديكورات وتر اجع أيضا من قبل مئل فئي

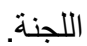

r م في حالة صلاحية سطح المبني الأثري إنثائيا

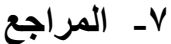

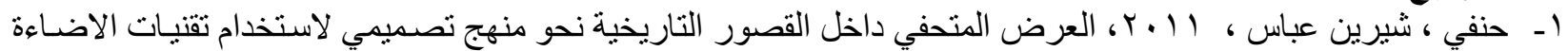

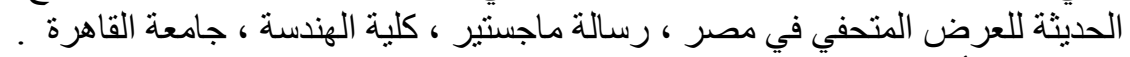

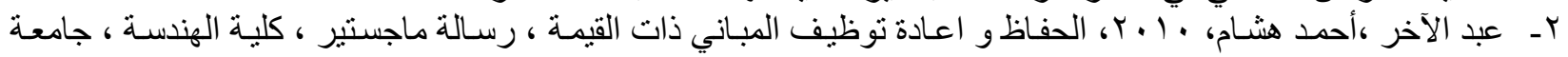

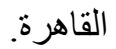

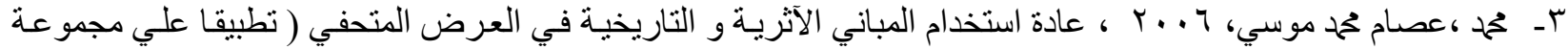

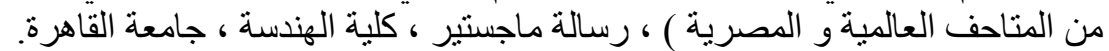

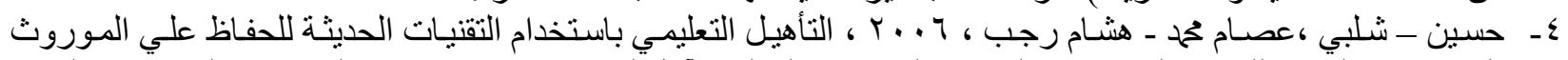

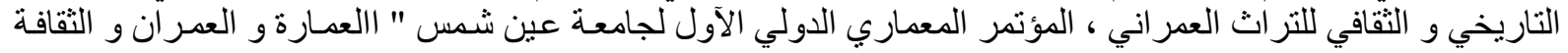

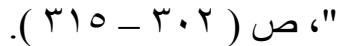

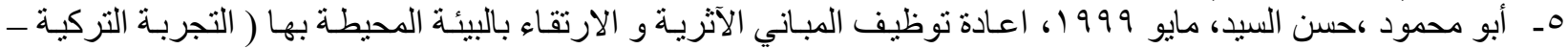

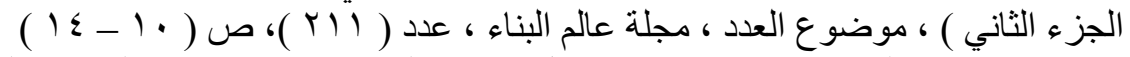

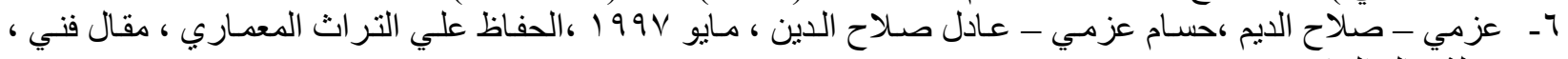

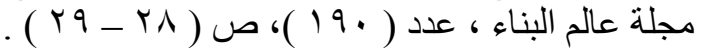

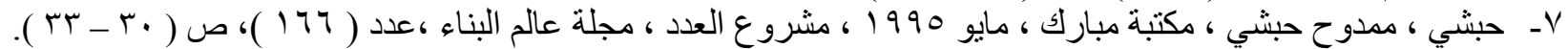

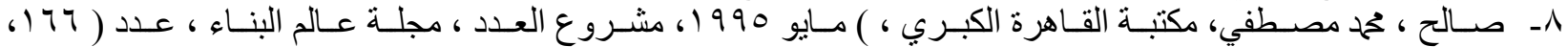
ص ص (rO

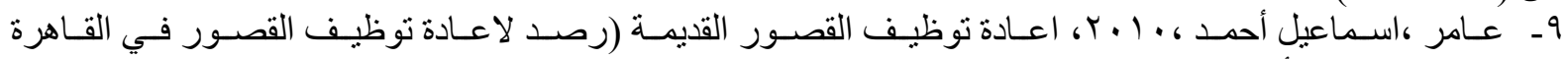
الكبري)،مجلة الأز هر.

10- Nihal M. Maarouf \& Nermin Mokhtar Mohamed , 2010 Towards A Sustainable Adaptation Of $19^{\text {th }}$ Century Residential Buildings In Egypt, Al-Azhar University Eleventh International Conference, CAIRO, Vol. 5, No. 6, page ( 531 - 544 ).

11- Https://Www.Elwatannews.Com/News, In 2019 Ad.

12-Https://Akhbarelyom.Com/News, In Oct 2019ad.

13-Https://Nourelrefai.Photoshelter.Com, In Oct2019ad.

14-Https://Www.Youm7.Com 